\title{
IDAHO NATIONAL LABORATORY RESEARCH \& DEVELOPMENT IMPACTS
}

Nicole Stricker

January 2015

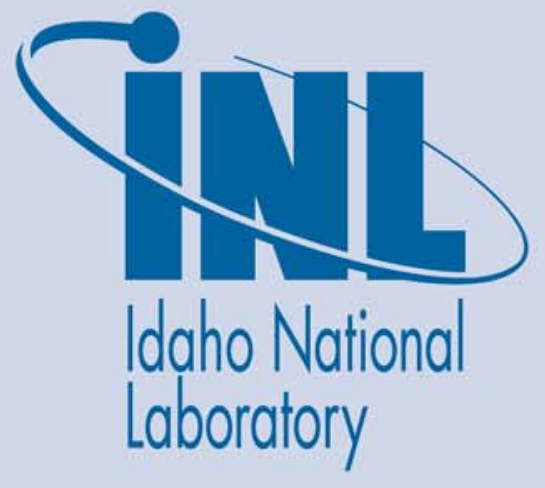

The INL is a U.S. Department of Energy National Laboratory operated by Battelle Energy Alliance 
INL/EXT-15-34218

\title{
IDAHO NATIONAL LABORATORY RESEARCH \& DEVELOPMENT IMPACTS
}

\author{
Nicole Stricker
}

January 2015

\begin{abstract}
Idaho National Laboratory
Idaho Falls, Idaho 83415
\end{abstract}

http://www.inl.gov

Prepared for the

U.S. Department of Energy

Office of Nuclear Energy

Under DOE Idaho Operations Office

Contract DE-AC07-05ID14517 


\section{Idaho National Laboratory Research \& Development}

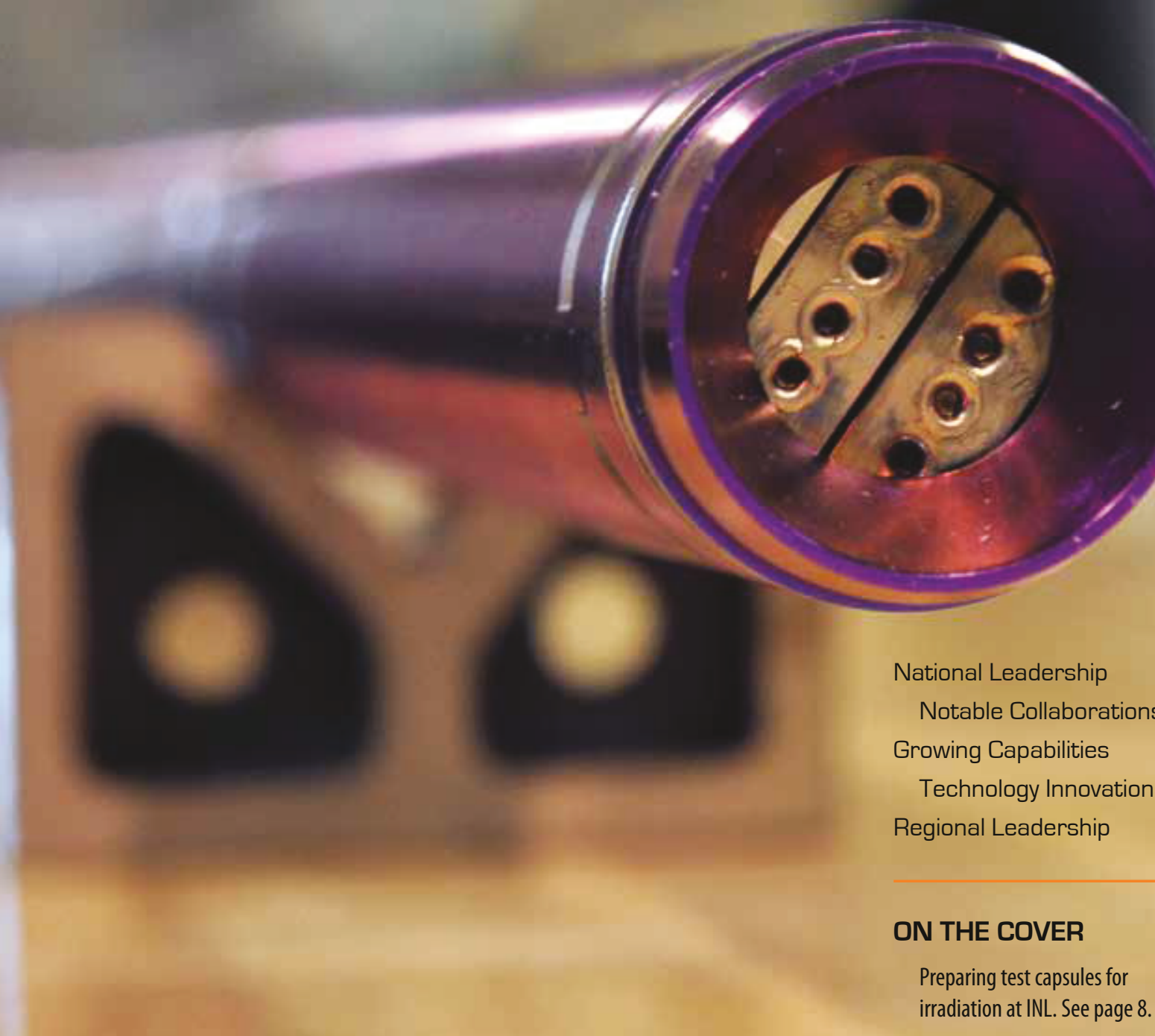




\section{FROM THE Director}

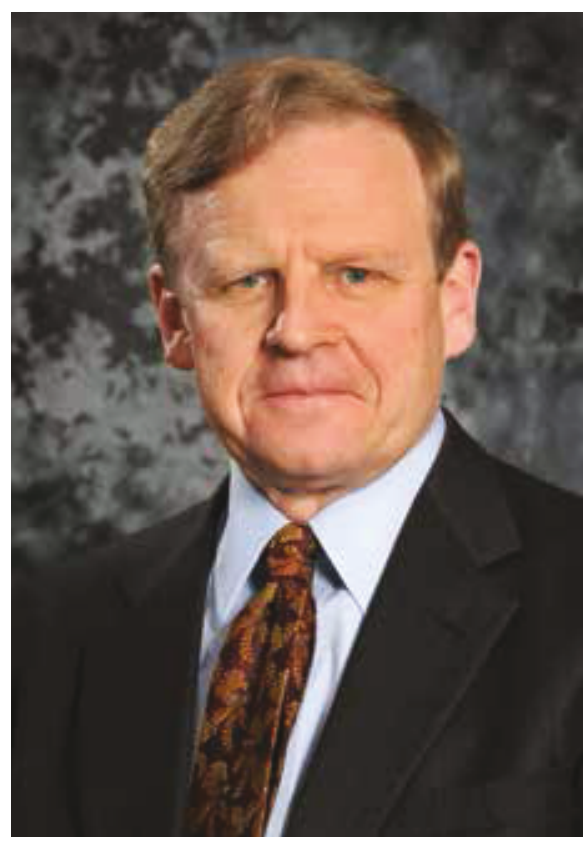

John Grossenbacher

Director, Idaho National Laboratory

\section{January 2015}

Technological advances that drive economic growth require both public and private investment. The U.S. Department of Energy's national laboratories play a crucial role by conducting the type of research, testing and evaluation that is beyond the scope of regulators, academia or industry. Examples of such work from the past year can be found in these pages.

Idaho National Laboratory's engineering and applied science expertise helps deploy new technologies for nuclear energy, national security and new energy resources. Unique infrastructure, nuclear material inventory and vast expertise converge at INL, the nation's nuclear energy laboratory.

Productive partnerships with academia, industry and government agencies deliver high-impact outcomes.

This edition of INL's Impacts magazine highlights national and regional leadership efforts, growing capabilities, notable collaborations, and technology innovations. Please take a few minutes to learn more about the critical resources and transformative research at one of the nation's premier applied science laboratories.

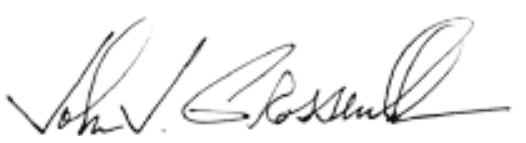

\section{On the cover}

Irradiation experiments in INL's Advanced Test Reactor begin with the preparation of material test capsules at the nearby Test Train Assembly Facility. Read more on page 8 .

\section{Editor: Nicole Stricker}

Writers: Suzanne Baker, Karen Bass, Ariel Conn, Corinne Dionisio Graphic artists:

Kristine Burnham, David Combs

Photographer: Chris Morgan

Prepared by Idaho National Laboratory, Idaho Falls, Idaho 83415.

Managed by Battelle Energy Alliance, LLC for the U.S. Department of Energy under contract DE-AC07-05ID14517.

\section{Disclaimer}

This report was prepared as an account of work sponsored by an agency of the United States

Government. Neither the United States Government, nor Battelle Energy Alliance, nor any of their employees, makes any warranty, expressed or implied, or assumes any legal liability or responsibility for the accuracy, completeness, or usefulness of any information, apparatus, product, or process disclosed, or represents that its use would not infringe privately owned rights. References herein to any specific commercial product, process, or service by trade name, trade mark, manufacturer, or otherwise, does not necessarily constitute or imply its endorsement, recommendation, or favoring by the U.S. Government or any agency thereof. The views and opinions of authors expressed herein do not necessarily state or reflect those of the U.S. Government or any agency thereof. Reference to the term Partner in this Report should not be construed as a legal relationship or the existence of a legal entity. 


\section{TABLE of Contents}

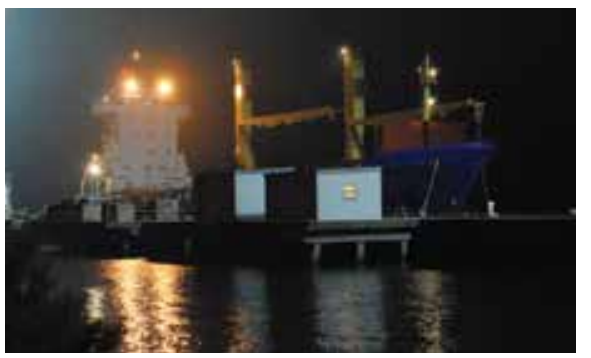

\section{National Leadership}

INL experts guiding work

toward national and international

energy solutions . . . . . . . . . 4

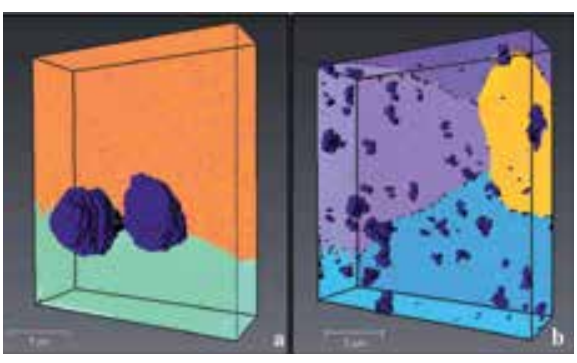

\section{Notable Collaborations}

Successful relationships with industry, academia and other government agencies . . . . . . . 8

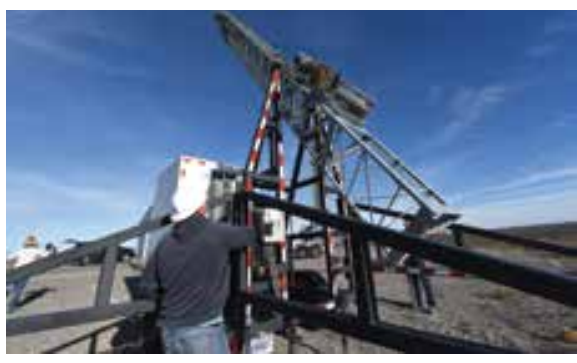

\section{Growing Capabilities}

Specialized applied science infrastructure

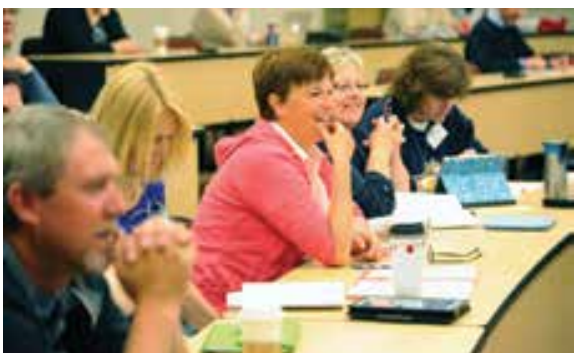

\section{Technology Innovation}

Innovations in nuclear energy, advanced energy, and national and global security............ 16

\section{Regional Leadership}

Multidisciplinary research efforts with government and academic partners. .............24

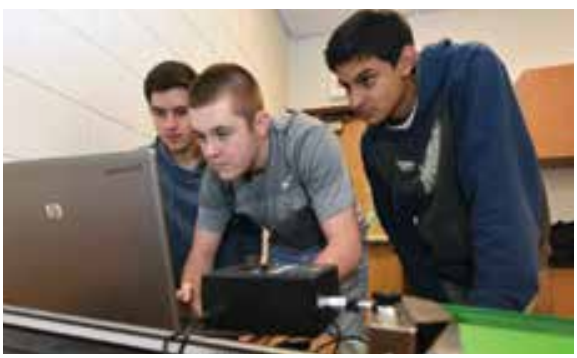




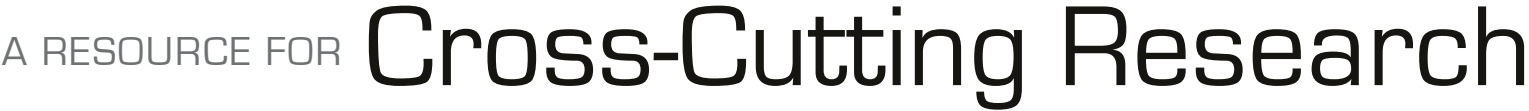

The U.S. today faces a number of challenges related to energy security, national security and cybersecurity. The Department of Energy [DOE] can deliver innovative and transformative scientific and technological solutions through its national laboratory complex.

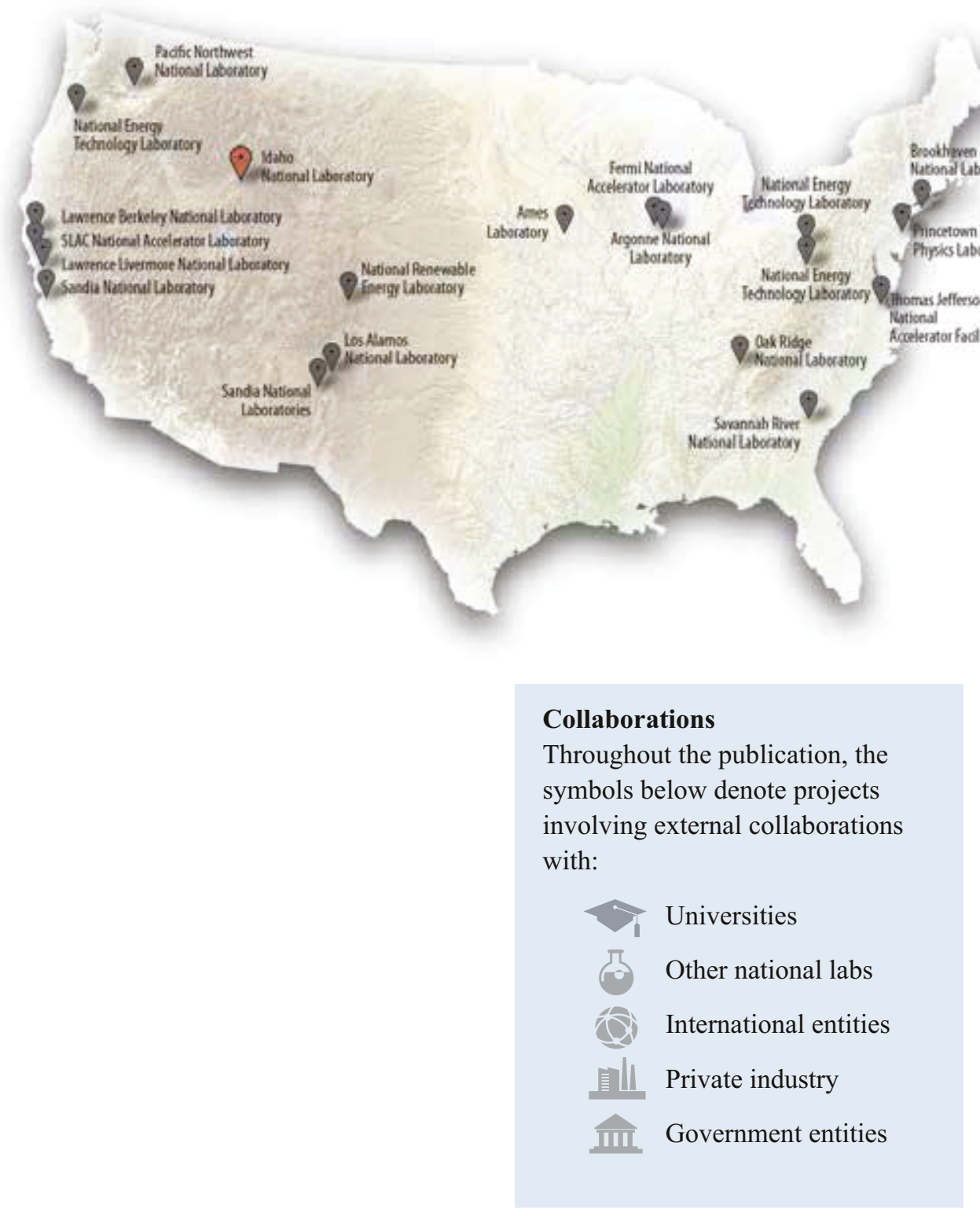

The laboratory embraces the user facility model, enabling access that makes INL's distinctive assets available to researchers across the nation. Consider INL's skilled staff and extensive partnerships, and a picture emerges of a national resource capable of addressing numerous current and future national challenges. 


\section{"When I talk about our security as a nation, our leadership}

\section{as a nation, it all begins with energy."}

\section{- Sen. Lisa Murkowski of Alaska, during an INL tour in March 2014}

For example, research agreements with entities spanning the nuclear energy enterprise allow INL to share proficiencies and research tools that are most relevant to private industry. Research and training related to nuclear security also reach throughout and beyond INL.

INL is leading work to bring about a step change in clean energy integration. For example, regional and international collaborations are studying the logistics associated with hybrid energy systems and electric grid resilience, stability and reliability. High-performance computing resources support modeling and simulation efforts in myriad research areas.

The laboratory's important work drew interest from a number of high-profile visitors in Fiscal Year 2014. In March, INL arranged a tour for the three most senior Republican members of the U.S. Senate Energy and Natural Resources

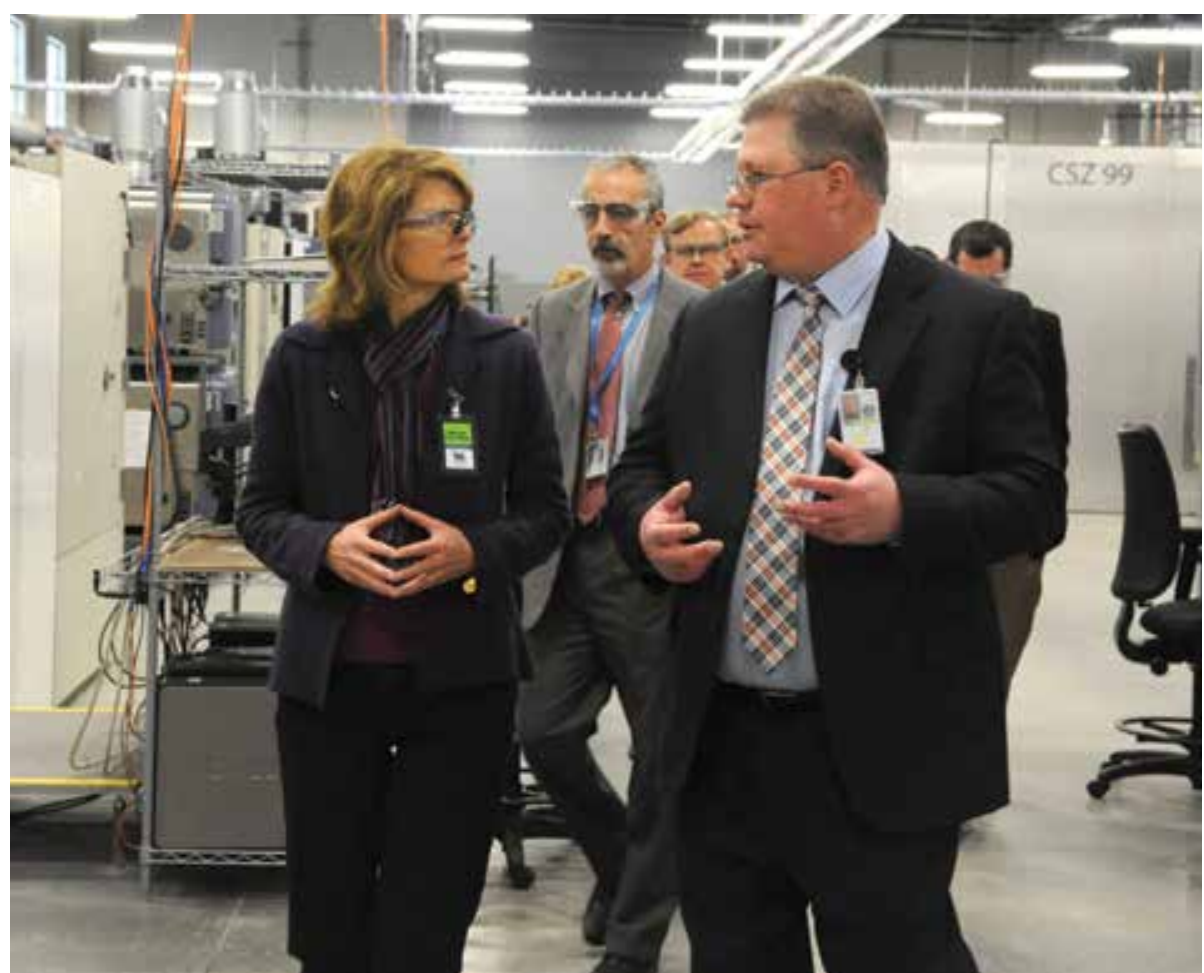

Committee, including Sen. Lisa Murkowski of Alaska. The laboratory also hosted visits from U.S. Energy Secretary Ernest Moniz and reporters from NOVA, The Economist and The New York Times.

Examples in the pages that follow illustrate some of the successes from the past year. Numerous productive partnerships are highlighted, along with enhancements to INL's state-of-the-art testing and evaluation capabilities. A handful of research accomplishments are described in the Technology Innovation section. Examples of regional leadership begin on page 24 . The final pages give a snapshot of INL's many distinguishing characteristics.

Overall, this partial summary of recent achievements illustrates how INL research innovation, testing and evaluation are helping apply new energy solutions to safely, securely and sustainably advance nuclear energy, protect infrastructure, expand energy supply and improve efficienc . 


\section{NatToNaL Leadership}

\section{Coordinating national solutions}

The DOE's national laboratories provide an invaluable resource to decision-makers, academia and private industry. As an objective source of expertise and analysis, national laboratories such as INL are uniquely qualified. Whether they're leading national discussions, coordinating diverse teams of specialists or making distinctive research assets available, INL experts are part of an important national resource.

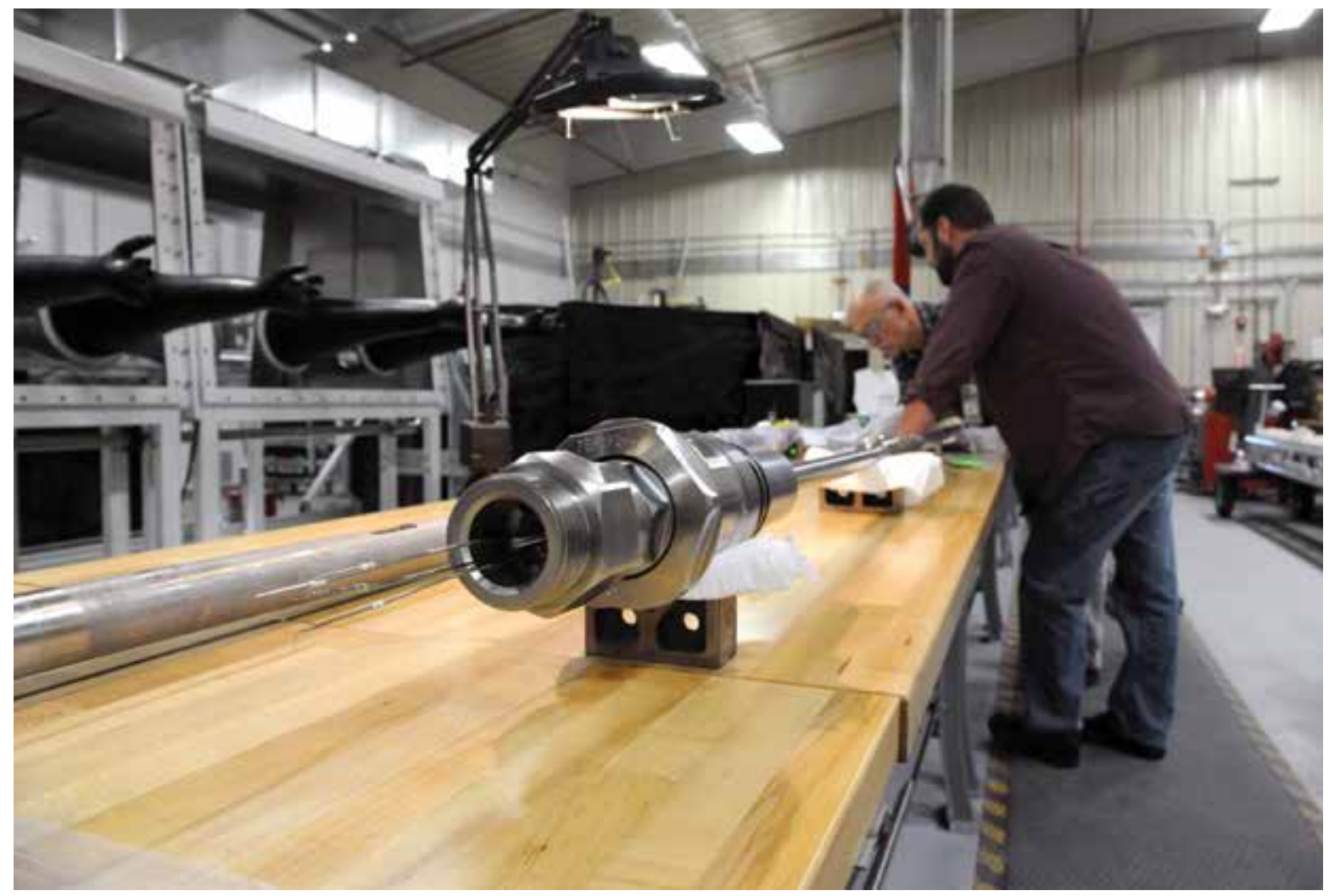

\section{Facilitating international cooperation}

There is significant international interest in the development of fuels with enhanced accident-tolerant characteristics. The Nuclear Energy Agency, part of an international economic and social wellbeing organization, established an international Experts Group to provide a forum for coordination. INL is chairing the group, which saw representatives from the U.S., Japan, China, Korea, Europe, Russia and the Czech Republic at its first meeting in late September.
Fuels with enhanced accident-tolerant characteristics are irradiated in experiment capsules assembled at INL's Test Train Assembly Facility. 


\section{Collaborating on waste management solutions}

A group of INL scientists was honored by the Secretary of Energy for its role as part of the Salt Waste Disposal Technologies Team. The team is composed of DOE program offices, national laboratories, industry and academia. The collaborative effort worked to combine fundamental and applied research, technology development, and other elements to deploy new technologies for the safe and cost-effective disposition of large volumes of radioactive salt waste. The outcome of this effort directly supported the closure of four waste tanks at DOE's Savannah River Site in Aiken, South Carolina.

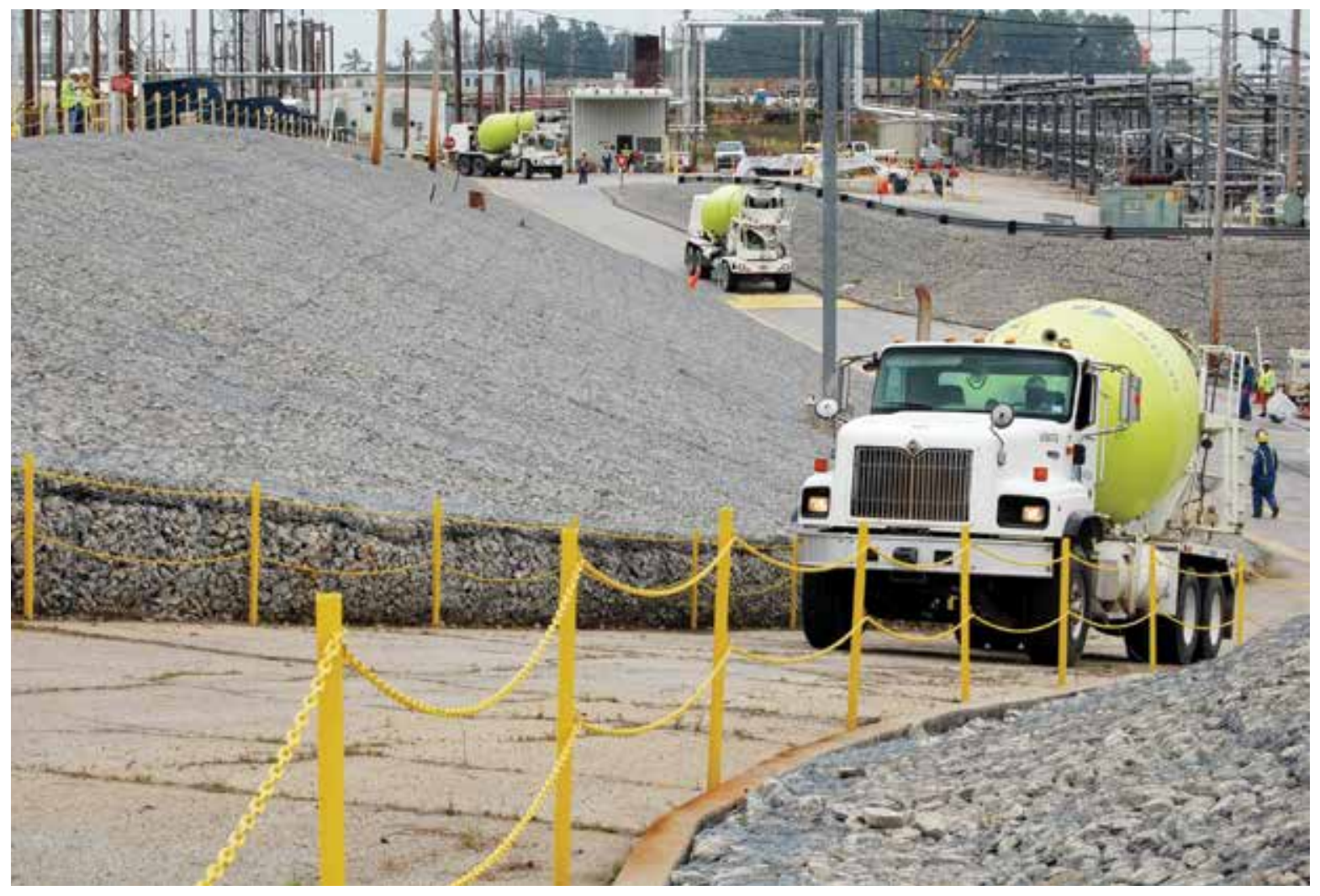

\section{Guiding international discussions}

INL Laboratory Director John Grossenbacher served as general chair for the 2014 American Nuclear Society Annual Meeting attended by nearly 900 people from 25 countries. The theme of the meeting was "The U.S. Role in a Global Nuclear Energy Enterprise." Numerous INL experts served in leadership positions that guided program development. 


\section{NatToNaL Leadership}

In FY 2014, INL offered a new International Atomic Energy Agency (IAEA) regional training course for state inspectors conducting cybersecurity assessments at nuclear facilities.

\section{Clean energy integration}

Hybrid energy systems combine hydrocarbon or nuclear with renewable energy resources to improve the efficiency of both electricity and heat generation. In addition to ongoing international partnerships, a new collaboration between the DOE's Office of Nuclear Ene gy (NE) and its Office of Energy Efficiency \& Renewable Ene gy (EERE) is seeking to integrate and harmonize advanced energy technologies through hybridization research and development. As a part of this partnership, INL has completed nuclear hybrid energy system feasibility studies for Wyoming and Utah. The impact of the program resulted in the NE-EERE Integration Workshop, which gathered state leaders, utilities, industry and universities to discuss game-changing regional hybrid energy systems.

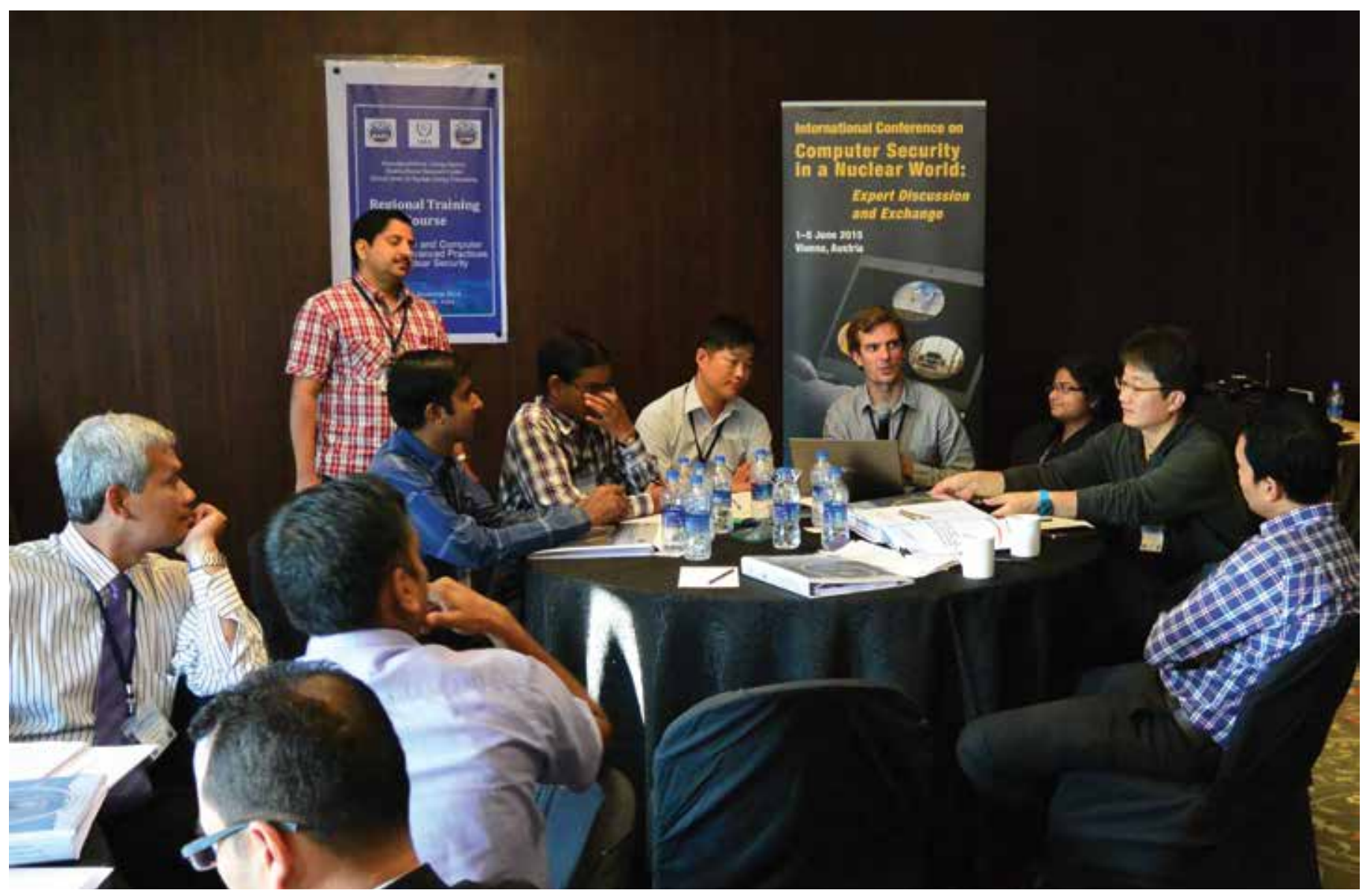




\section{Supporting emergency response}

Information for emergency planning and response exists in vast, diverse and largely unsearchable databases owned by government agencies such as the Department of Homeland Security. INL's Digital Library now provides a public, searchable tool for accessing such information. The software uses a novel approach to integrate large amounts of data for assessing vulnerabilities arising from a natural or human-caused disaster. The suite of products ultimately won a Computerworld Editors' Choice Award. 孟

\section{Preparing for potential threats}

To ensure the nation is ready to respond to a radiological emergency, INL's technical experts supported 26 Radiological Dispersal Device (RDD) Emergency Response Training sessions. These sessions trained approximately 350 emergency responders within Federal Bureau of Investigation, Navy Explosives Ordnance, state Hazardous Material (HazMat) and urban emergency response teams, including public safety organizations within Idaho. Additionally, INL participated in 13 Radiological Assistance Program (RAP) national preparation exercises and team activation events. 요

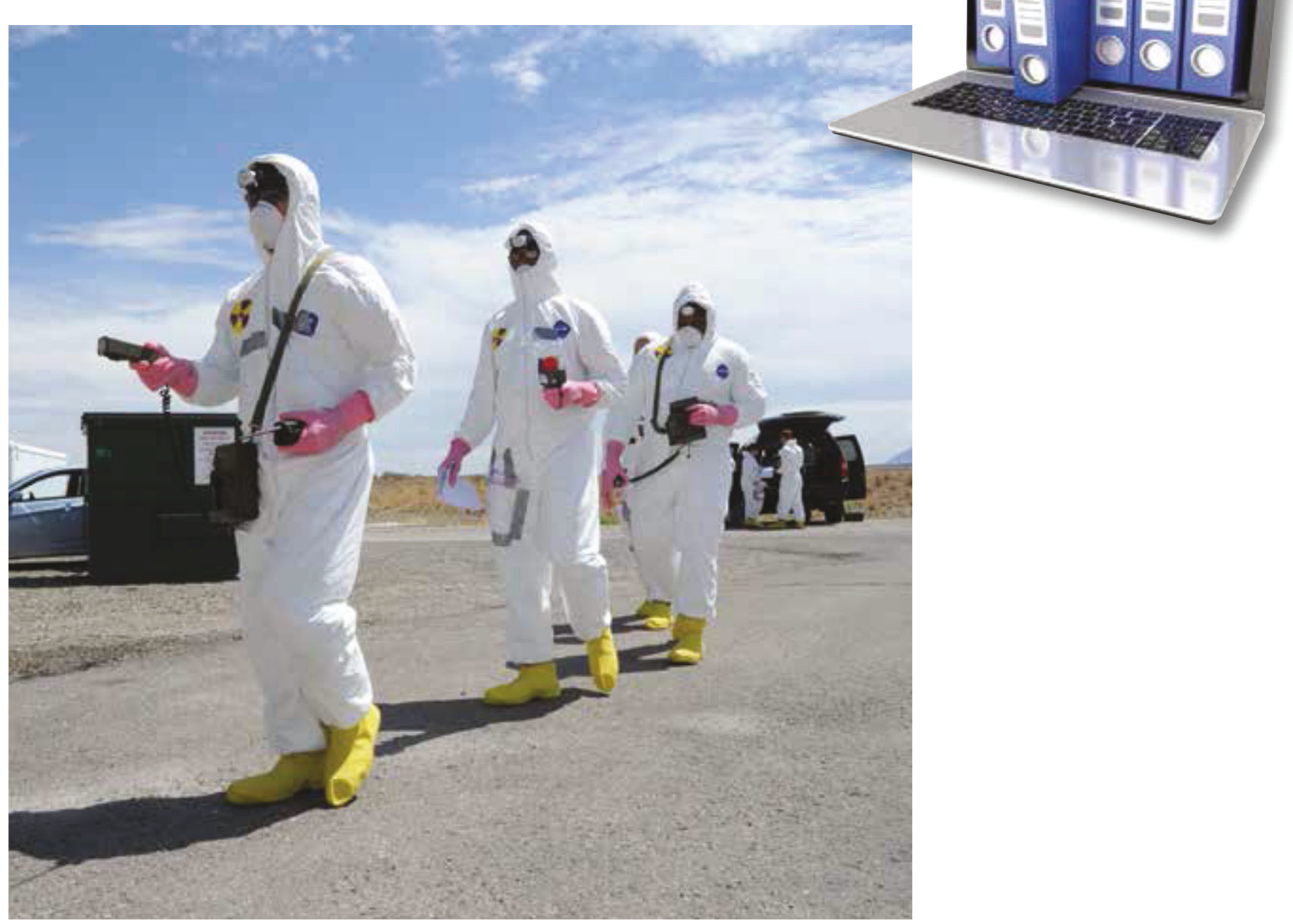




\section{NoтAвLECollaborations}

\section{Sharing access to national assets}

DOE's national laboratories enable research and development that falls outside the scope of industry or academia. Collaboration with entities beyond DOE expands access to public research assets and helps achieve nationally significant results. Through university partnerships and collaborations with industry, INL is able to share relevant capabilities to foster advanced scientific discovery and deploy new technologies for economic growth.

Irradiation experiments, such as the "compact tension" specimens below, are prepared at INL's Test Train Assembly Facility shown at right.

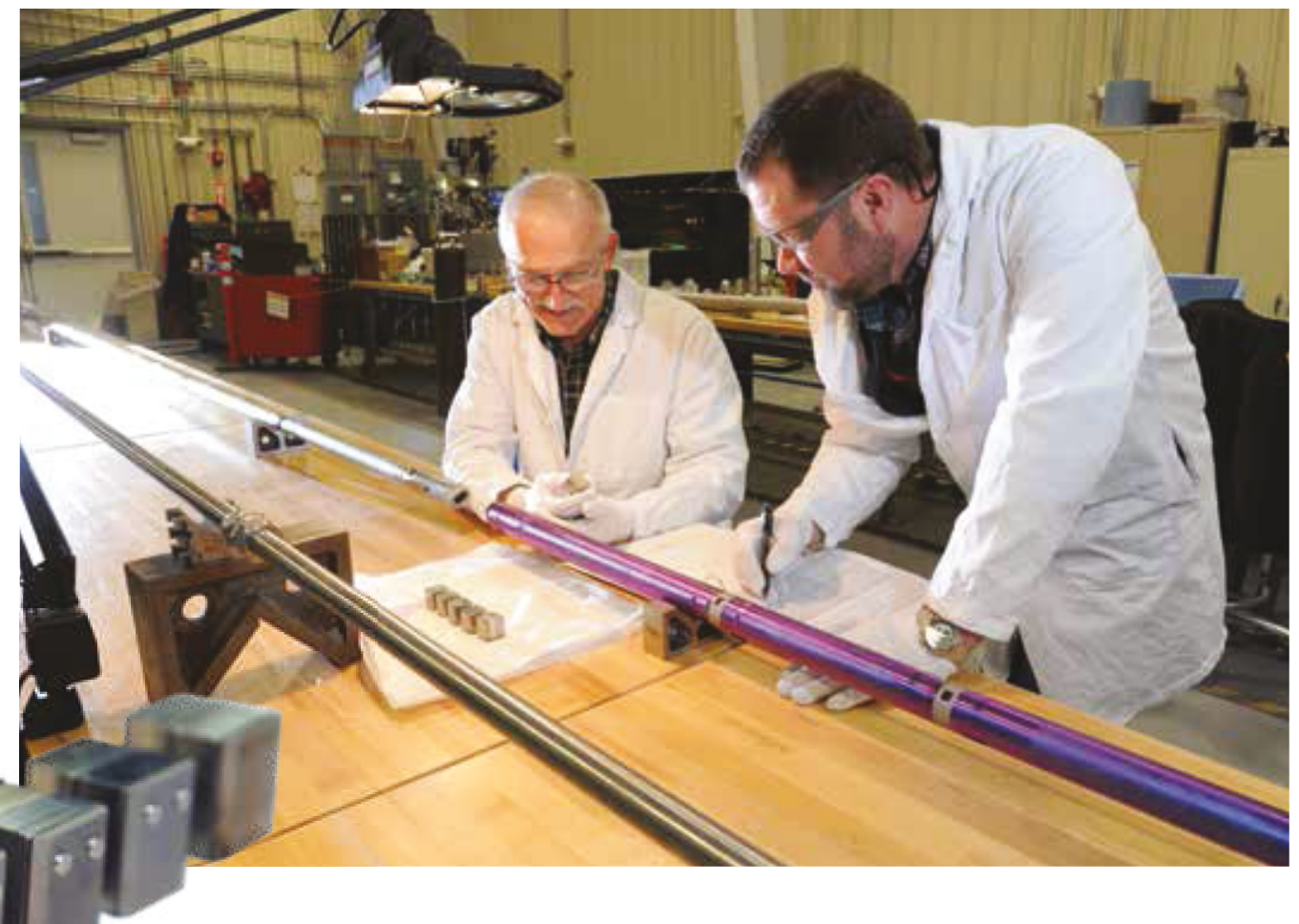

Improving knowledge of radiation effects

Nuclear reactors supply more than 60 percent of the nation's emissionfree electricity. Understanding how radiation affects both fuel and reactor components is critical for the continued safety and reliability of existing light water reactors, as well as for improving advanced reactor materials. Irradiation capabilities at INL's Advanced Test Reactor (ATR) and postirradiation examination (PIE) at the Materials and Fuels Complex are available for industry use. For example, INL and the Electric Power Research Institute (EPRI) are working together to measure IrradiationAssisted Stress Corrosion Cracking in a new reactor alloy. INL's globally unique IASCC test rigs can characterize crack growth and other

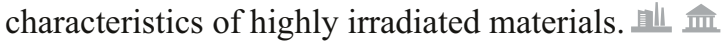




\section{notaвle Collaborations}

\section{Improving efficiency during plant outages}

The Nuclear Energy Institute awarded a Top Industry Practice award to INL and Arizona Public Service for outage control center technology developed by DOE's Light Water Reactor Sustainability program. The advanced instrumentation, information and control technologies improved refueling outage performance and increased efficiency during the Palo Verde Nuclear Generating Station's Fall 2013 refueling outage, saving an estimated $\$ 48$ million. 넨

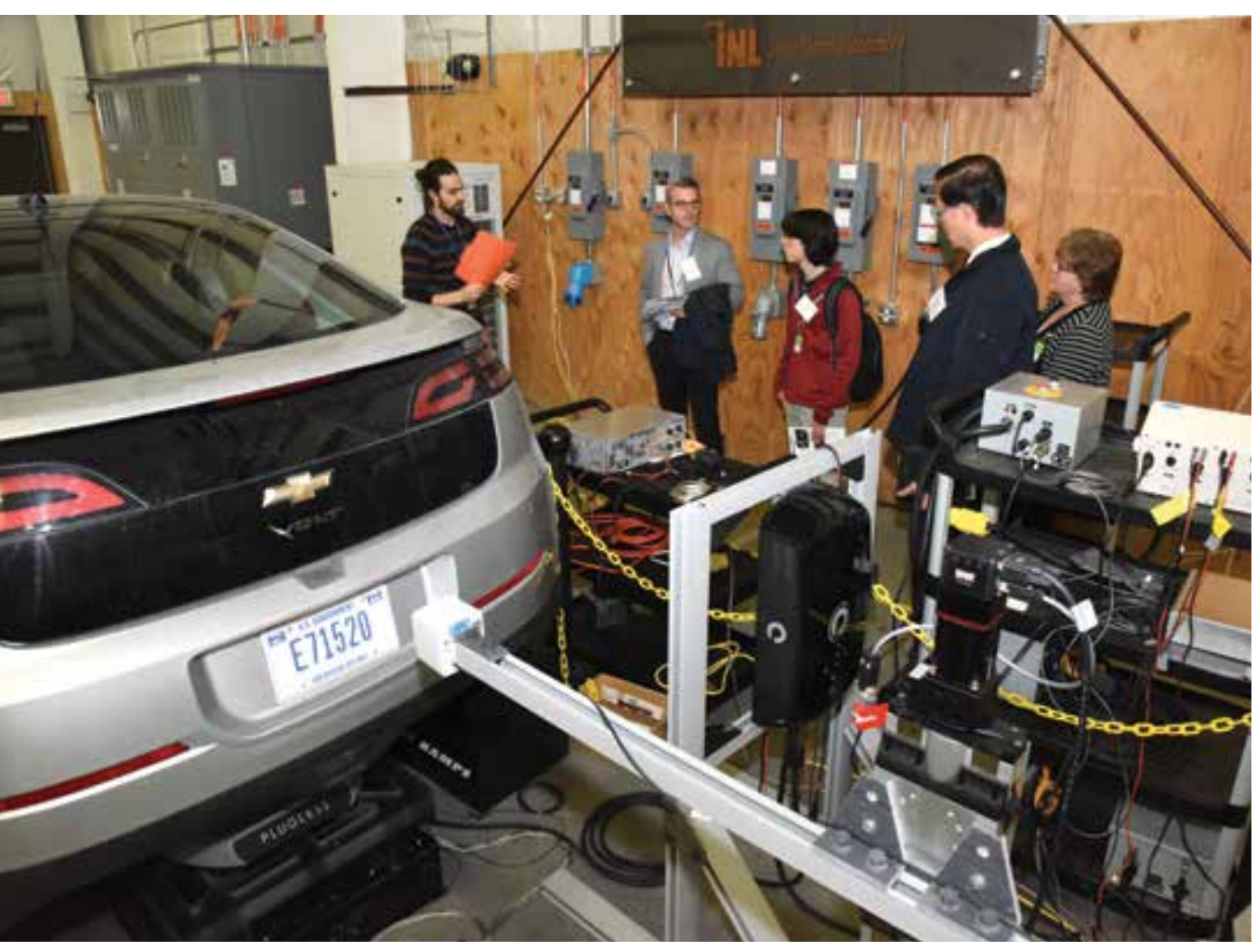

Improving nuclear energy infrastructure cybersecurity Cybersecurity is an important component for assuring the security of the global nuclear energy enterprise. The International Atomic Energy Agency (IAEA) has recognized INL as a key contributor in this area. INL expertise and methodologies have informed approaches the IAEA uses to implement threat analysis and cybersecurity. By providing cybersecurity support to nuclear energy infrastructure owners, operators, regulators and supervisory groups, INL is helping advance the state of nuclear cybersecurity to ensure that global use of nuclear energy continues to be safe and secure.

\section{Advancing vehicle battery and cybersecurity testing}

INL's advanced vehicle battery and cybersecurity testing of smart electric vehicle charging is helping define industry standards. INL completed the first-ever independent testing of a "plugless" wireless charging system for electric vehicles, proving that wireless charging works and is safe. INL also completed the first cybersecurity testing of General Electric's Smart electric vehicle charging system. Data from this testing is helping set wireless charging performance standards for the Society of Automotive Engineers. 


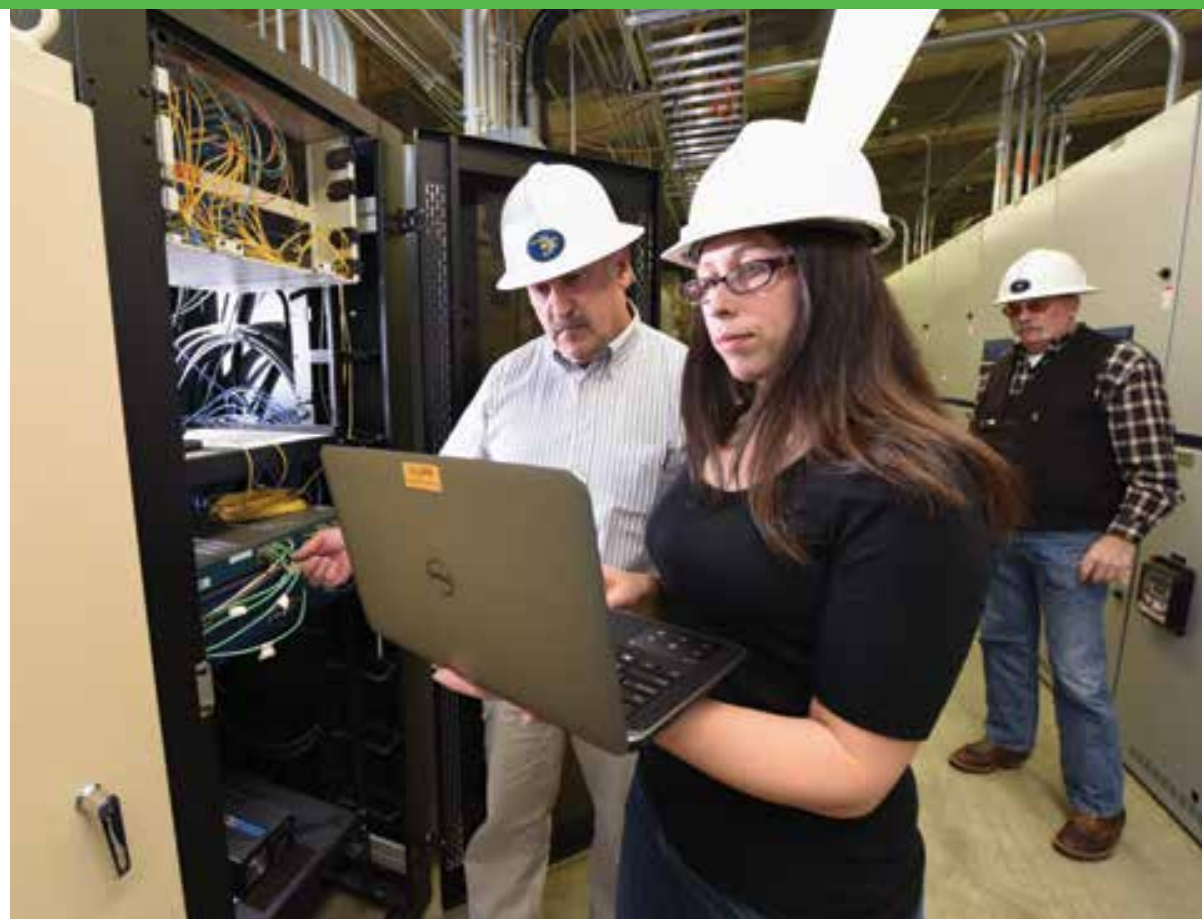

Protecting from solar storms

Solar flares and sunspot cycles can disturb or even interrupt power and communications systems for extended periods of time. First-of-a-kind tests at INL's full-scale power grid test bed already have led to the development of technologies that help protect the grid from the effects of such geomagnetic disturbances. The Defense Threat Reduction Agency (DTRA) has designated INL as a Grid Center of Excellence for Geomagnetic Disturbance Effects for conducting experiments that will protect the nation's energy infrastructure. INL's site was selected for its distinctive capabilities, technical expertise and security after reviews of national power grid testing locations. 표

\section{"IAEA and INL ... worked together to provide a path forward, integrating the disciplines} of cyber and physical security within the nuclear security framework."

\section{- Khammar Mrabit, IAEA's Director of Nuclear Security}

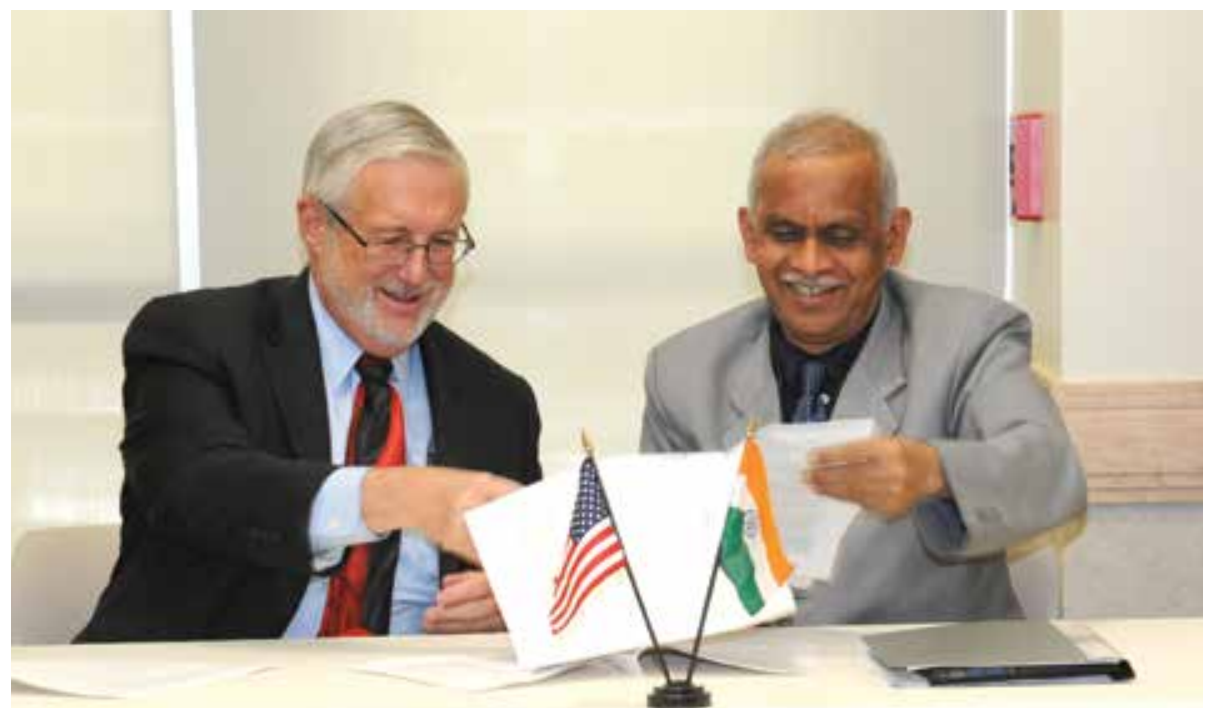

DOE Assistant Secretary for Nuclear Energy Dr. Peter Lyons hosted a visit to INL by members of the 6th Indo-U.S. Civil Nuclear Energy Working Group. The visit included a delegation from India's Department of Atomic Energy and its Bhabha Atomic Research Centre. 


\section{въомим Capabilities}

\section{Strategic Infrastructure}

INL is continually upgrading an irreplaceable array of scientific and engineering capabilities that can address a variety of energy research needs today and in the future. This complement of capabilities supports a multiprogram laboratory with broad competencies in energy and national security.

\section{Green building recognition}

The Energy Innovation Laboratory (EIL)

building is a state-of-the-art research facility that earned Platinum certification for Leadership in Energy and Environmental Design (LEED) based on water efficienc, energy consumption, materials, indoor environment quality and design innovation. The reconfigurable open labs house research for both DOE-NE and DOE-EERE. EIL is the first laboratory facility in the state of Idaho to achieve the highest level of LEED certification.

The EIL project team won Engineering News-Record's Best 2014 Green Project in the nation award and the Best Overall Intermountain Project award. The International Institute for Sustainable

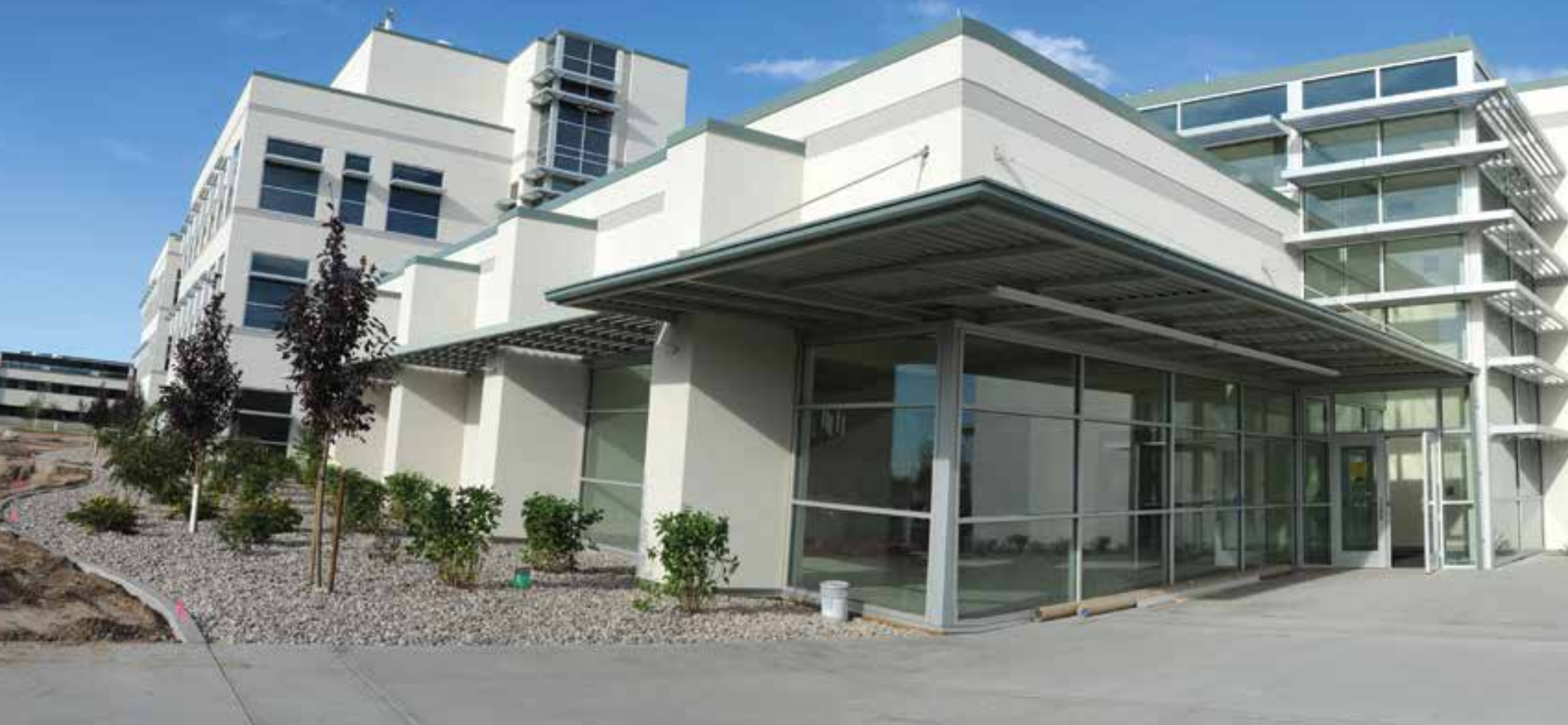


Laboratories (I2SL) also granted EIL the 2014 Go Beyond Award. These awards celebrate the integration of environmentally sustainable technology and materials during design and construction.
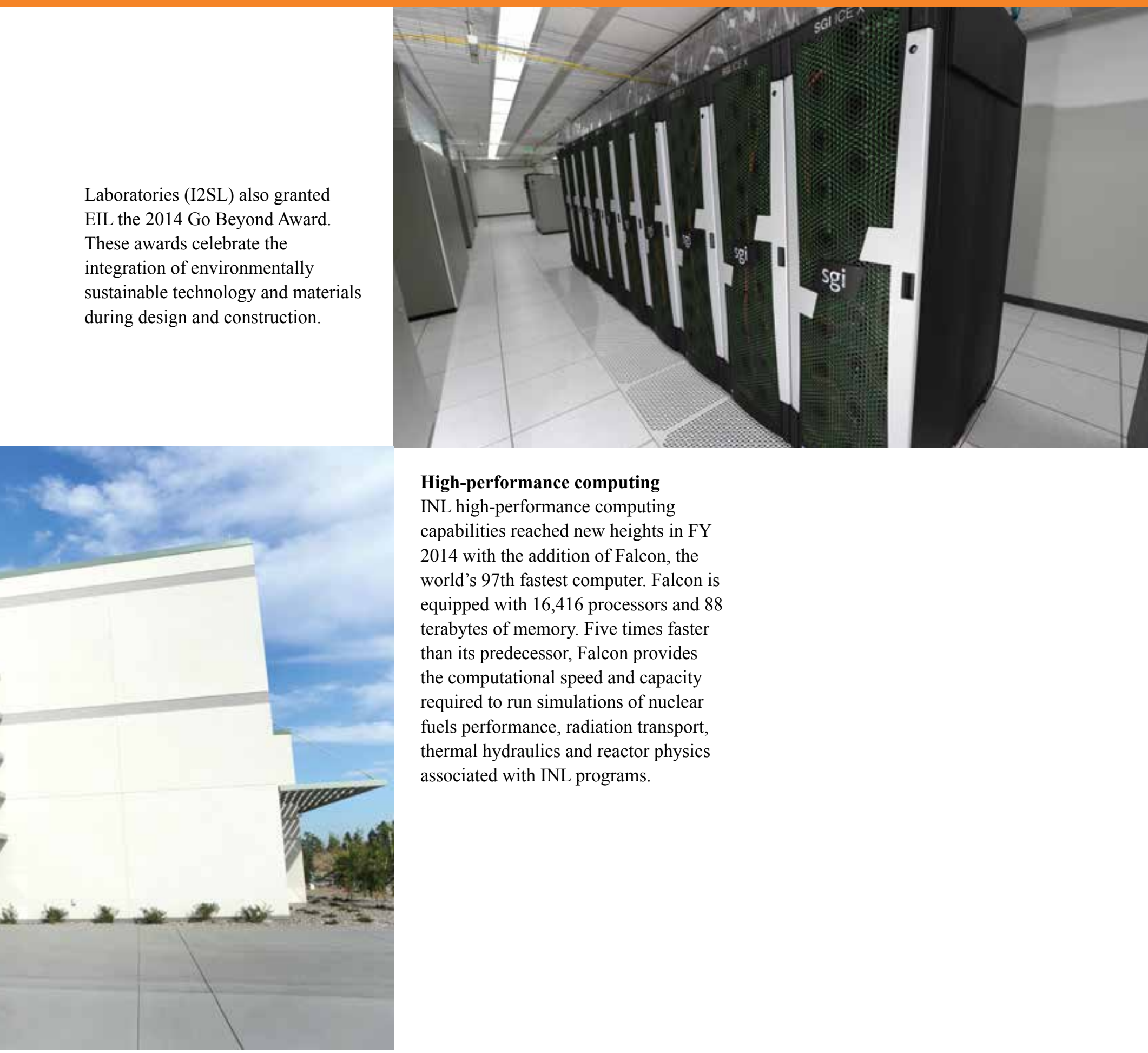

\section{High-performance computing}

INL high-performance computing capabilities reached new heights in FY 2014 with the addition of Falcon, the world's 97th fastest computer. Falcon is equipped with 16,416 processors and 88 terabytes of memory. Five times faster than its predecessor, Falcon provides the computational speed and capacity required to run simulations of nuclear fuels performance, radiation transport, thermal hydraulics and reactor physics associated with INL programs. 


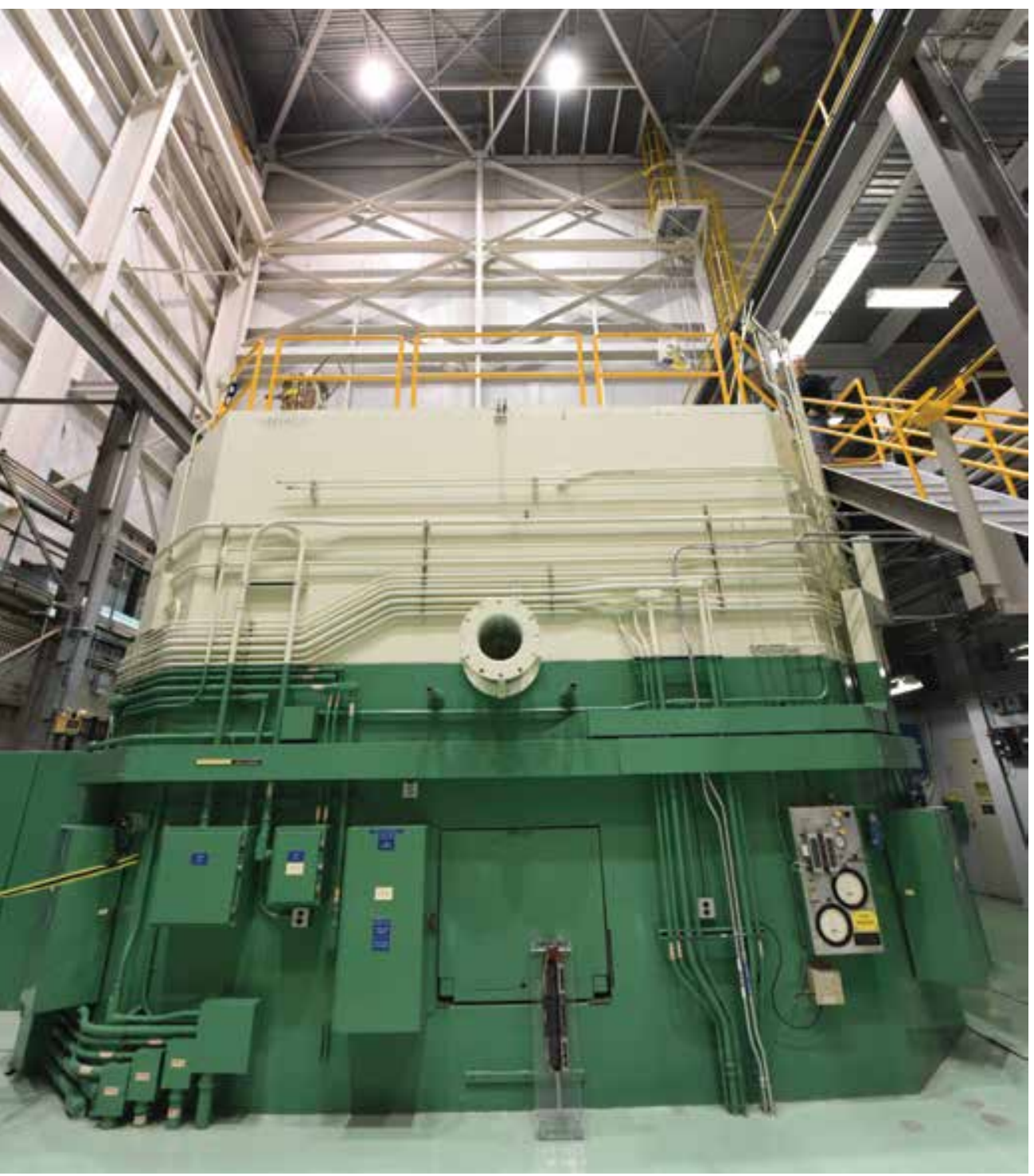

INL is resuming operations at the Transient Reactor Test (TREAT) Facility, which has the potential to provide scientific data and research opportunities unlike any other facility in the world. After minor modifications to resume testing at TREAT, thanks to superb upkeep and late-1980s renovations, TREAT will help scientists test and qualify new nuclear fuels.

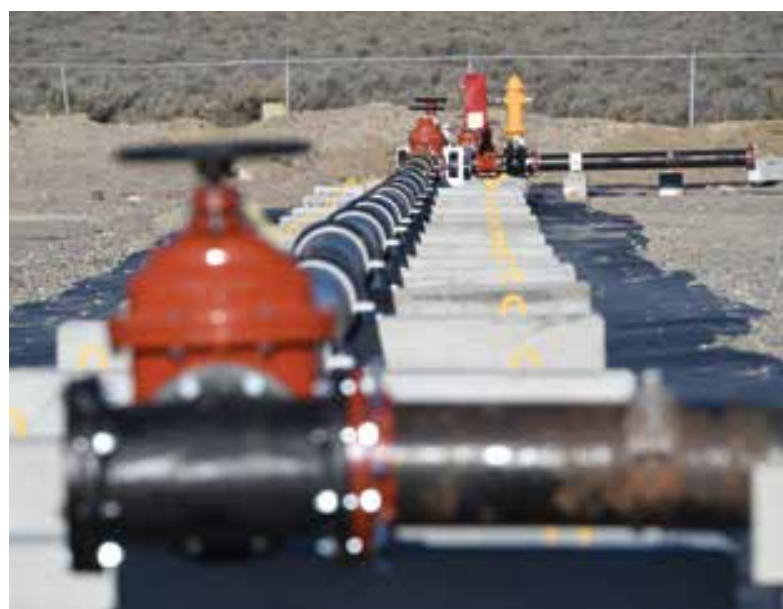

The Water Security Test Bed at INL replicates a municipal drinking water piping system to test lab- and pilotscale approaches to contamination detection and water treatment using simulated contaminants.

"It is very exciting and will provide a tremendous integrated asset. There will be people coming to INL from all over the world to do this work. It's important to the future of nuclear power." - U.S. Energy Secretary Ernest Moniz on restarting the TREAT reactor facility at INL 


\section{Technology inNovation}

\section{The forefront of innovation}

INL is a multiprogram laboratory with mission areas spanning nuclear and energy research, applied science and national defense. INL has distinctive technical and cross-disciplinary capabilities. The following pages describe cutting-edge developments from the past year, as well as the people behind the technologies. The benefits of these far-reaching advances support industry, security and beyond.

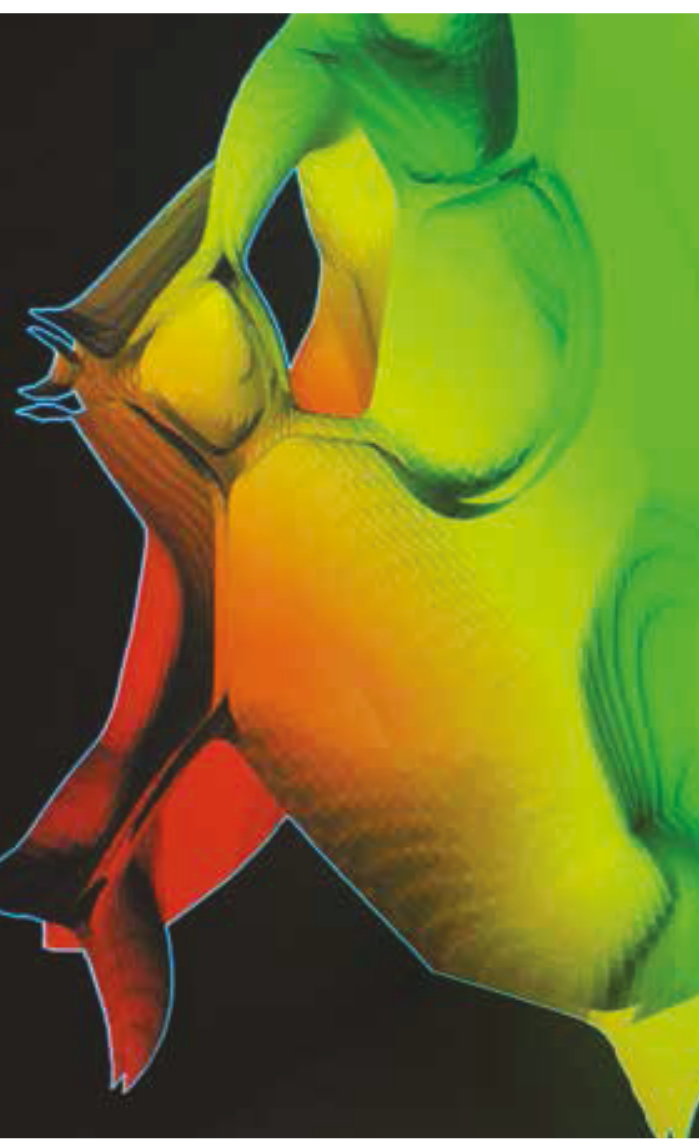

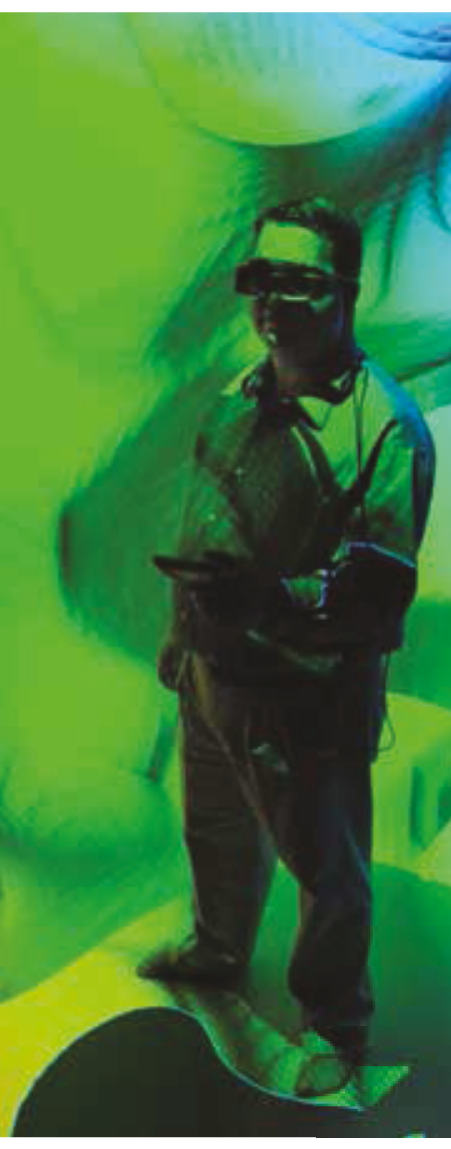

Michael Tonks, above, is an INL computational materials scientist working with INL materials engineer Melissa Teague to feed data from firstof-a-kind microscopic studies on nuclear fuel into a model for nuclear fuel microstructure.
Modeling the way to advanced nuclear fuel design

Two INL researchers are exploring the 3-D microstructure of irradiated nuclear fuel, then feeding that data into cutting-edge fuel behavior models. Their work helps to guide the development of safer nuclear fuel with enhanced performance and is capturing attention from international scientists.

The computational investigation is focused on microscale changes in irradiated fuel, which researchers have long pondered but never seen in 3-D. The information can reveal how and why certain materials perform better than others. It can also make testing and validation more efficient by reducing the number of time-consuming irradiation experiments required to qualify a new material. 


\section{New examination approach yields nuclear fuel insight}

It is essential for engineers to understand how new fuel types stand up to prolonged irradiation before these materials are used in commercial power reactors. But such understanding can be a challenge when it comes to handling and studying extremely radioactive materials. INL researchers recently demonstrated a new sample preparation technique that makes it easier to examine irradiated fuel at the nanoscale. The new technique mills the material with an ion beam to yield sections that are just tens of nanometers thick. Their initial findings suggest enhanced irradiation stability of a new type of reactor fuel.
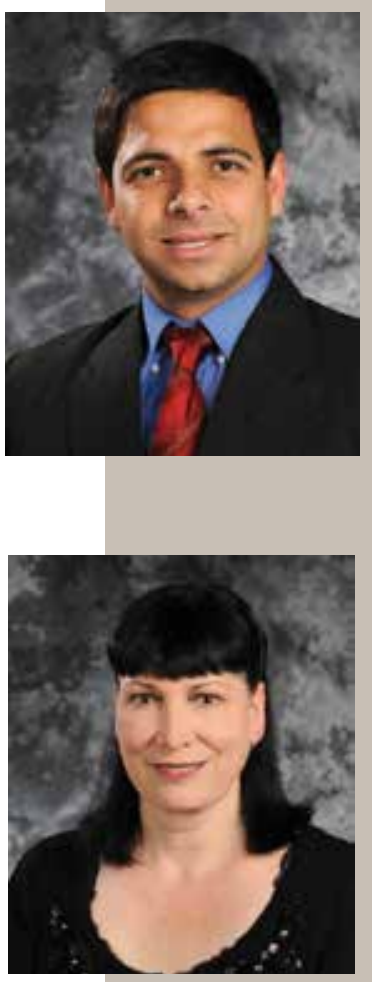

\section{Catherine Riddle}

The nuclear science and technology researcher was honored by the DOE 2014 Innovations in Fuel Cycle Research Awards Program. She won first place in the "Competition for Students Who Attend Universities with less than $\$ 600$ Million in 2012 R\&D Expenditures."

\section{Troy Unruh}

The research and development engineer at INL's High Temperature Test Laboratory won second place in the Advanced Fuels Category of the DOE 2014 Innovations in Fuel Cycle Research Awards Program. Troy also won the New Investigator Award from the Idaho Academy of Science. 


\section{Technology mnovaton}

"The MOOSE team has managed to find that elusive balance between flexibility and

usability, and their method of coupling different physics is incredibly exciting for me;

suddenly collaboration with a wide variety of other researchers is possible, and we

are looking forward to tackling some very complicated cross-discipline problems."

— researcher with Australia's Commonwealth Scientific

and Industrial Research Organization

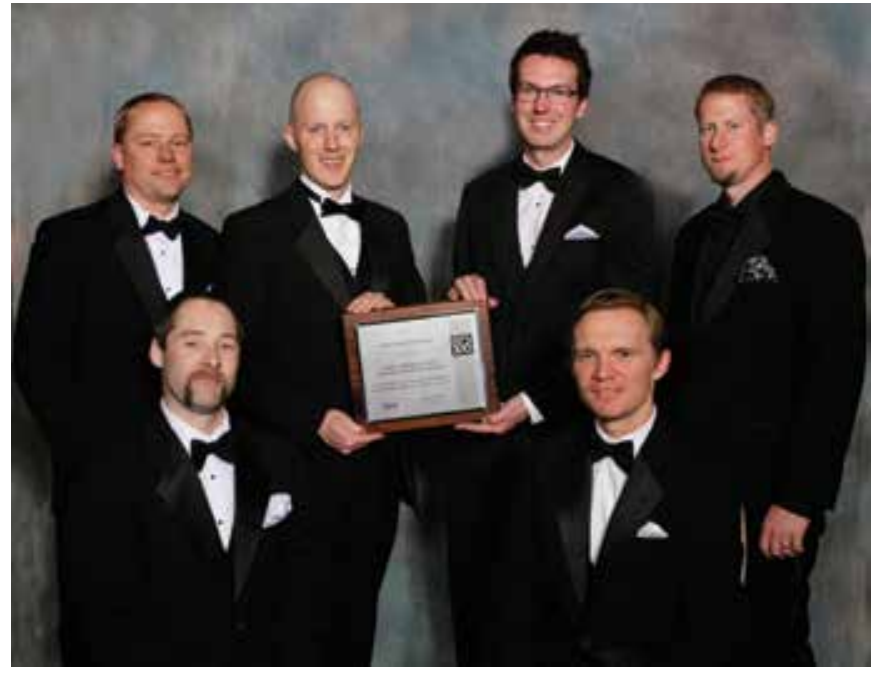

The MOOSE development team includes (from left): John W. Peterson, Jason Miller, Cody Permann, Derek Gaston, David Andrš and Andrew Slaughter.

\begin{abstract}
Award-winning modeling \& simulation tool goes open source INL's Multiphysics Object Oriented Simulation Environment (MOOSE) makes modeling and simulation more accessible to a broad array of scientists. MOOSE has revolutionized predictive modeling, especially in the field of nuclear engineering - allowing scientists to develop complex applications that simulate fuels and materials behavior under operating and accident conditions. In 2014, the technology was made available via open source software licensing and won an R\&D 100 Award and a Federal Laboratory Consortium Far West award for Outstanding Commercialization Success.
\end{abstract}




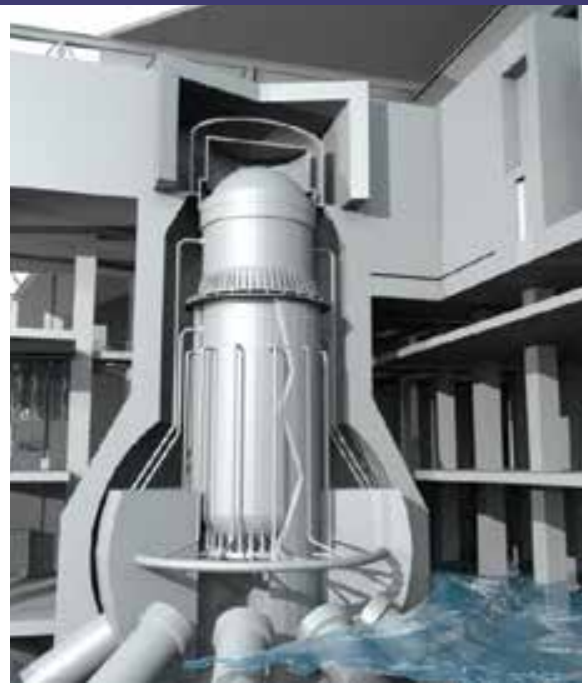

\section{Comprehensive risk analysis for nuclear power plants}

Safe nuclear plant operations demand that risk associated with nuclear energy technologies be quantified and analyzed. The Risk-Informed Safety Margin Characterization (RISMC) methodology developed at INL helps researchers identify and model risk factors through a combination of physics models and probabilistic methods. In 2014, RISMC expanded to include analysis of external events, like seismic activity and flooding. New stakeholders, including the South Texas Plant and the Nuclear Regulatory Commission, have partnered with INL to support the continued development of RISMC. International interest is also increasing with Japanese and European institutions proposing collaborative work.

\section{Recognizing Expertise}
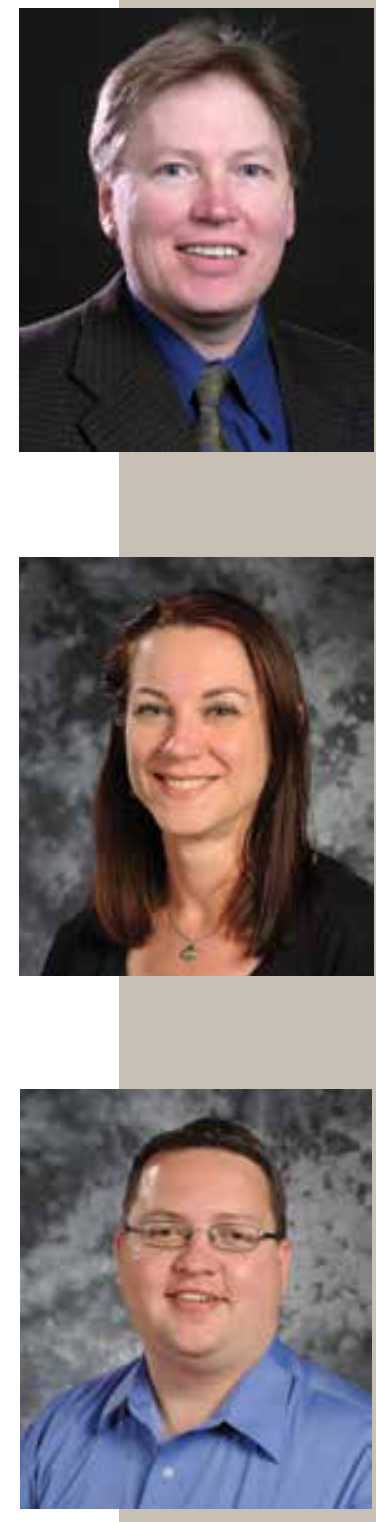

\section{Bruce Hallbert}

The director of Nuclear Energy

Enabling Technologies was among the recipients of a Nuclear Energy Institute Top Industry Practice Award. This is the first time IN researchers have been honored with NEI's top distinction (more info on page 10).

\section{Heather Chichester}

The technical lead for the Advanced Fuels Campaign Irradiation Testing was recognized by the American Nuclear Society Materials Science and Technology Division, which presented her with the 2012 Past Chair Award for her dedication to the leadership and advancement of the Materials Science and Technology Division of ANS.

\section{Michael Tonks}

The computational materials scientist was among the winners of The Minerals, Metals and Materials Society 2014 Young Leader Professional Development Award. He also won INL's 2014 Laboratory Director's Award for Early Career Exceptional Achievement. 


\section{Technology innovation}

\section{"Meeting at your site}

\section{was invaluable ... The}

important work that INL

\section{is doing for our country}

was observed all day.

I am still in awe."

- industry representative

from U.S. Council for

Automotive Research

[USCAR]

Experimental lithium-ion cells in an environmental test chamber at one of INL's battery test facilities.
Improving batteries with modeling As demand grows for increasingly efficient batteries, the science of performance becomes more important. Electrolytes act as the conductive medium within a battery and can significantly impact how long a battery lasts. Companies and researchers dedicate countless hours and resources to determining which electrolyte-battery pairing best suits their needs. The Advanced Electrolyte Model (AEM) developed at INL is a simulation tool that uses electrolyte metrics to evaluate and compare more than 35 parameters to recommend optimal solutions. Using the AEM has helped cut down research time for companies by as much as 70 percent. The AEM won a 2014 R\&D 100 Award and an Early Stage Development Technology award from the Federal Laboratory Consortium Far West Division. 넨

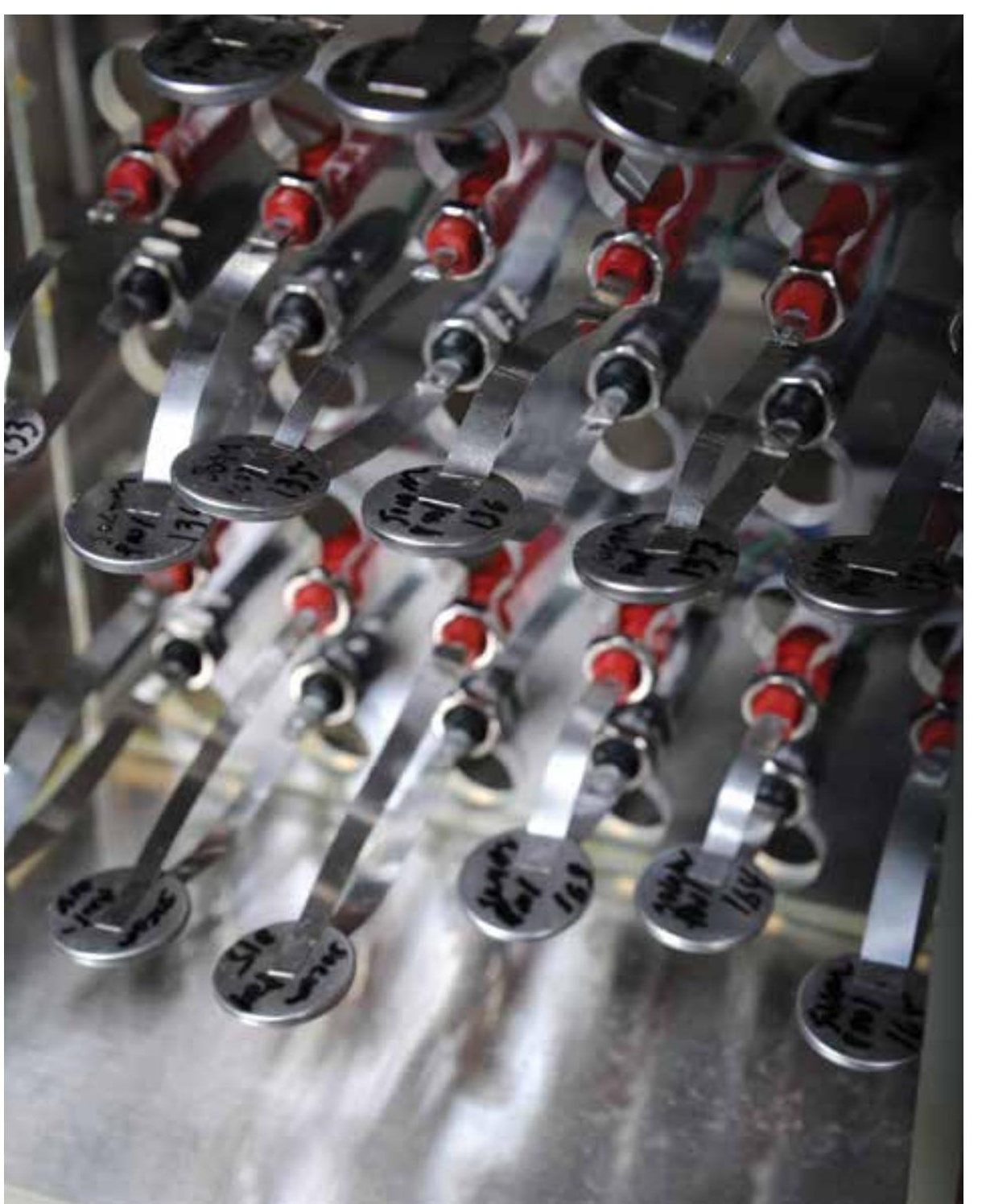




\section{Accelerating clean transportation}

Increasing affordable plug-in electric vehicle (PEV) use within 10 years is part of the EV Everywhere Grand Challenge President Obama issued in 2012. By collecting and analyzing data from thousands of privately owned electric vehicles, INL researchers are learning how current PEV charging stations are used and can be improved.

INL has published information about regional use patterns, the effects of workplace charging, what improvements the charging stations need and barriers to station deployment. Researchers detailed first-of-a-kind results at the 2014 Society of Automotive Engineers (SAE) World Congress Conference. This work helps validate SAE electric vehicle performance standards.

\section{Advancing sustainable manufacturing}

Critical materials and Rare Earth Elements are crucial for advancing clean energy technologies, but can be difficult and expensive to obtain. IN has extracted similar materials from nuclear fuels and is well-suited to purify critical materials from unique sources such as used smartphones or computer devices. In 2014, INL researchers laid the foundation for work with the Critical Materials Institute led by Ames National Laboratory. Installation and testing began for a state-of-the-art pilot demonstration that will establish new methods of purification. Researchers also provided insight into the supply and demand chain at a congressional hearing.

\section{Recognizing Expertise}

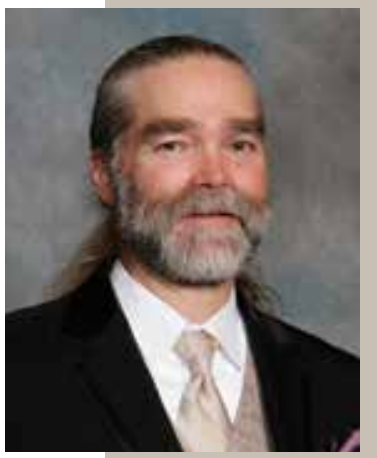

\section{Kevin Gering}

This lead scientist won a prestigious 2014 R\&D 100 Award for developing the Advanced Electrolyte Model (AEM), an effort that spanned 12 years. This model earned praise from industry for its ability to improve efficiency in battery development. Kevin has worked at INL for more than 20 years..

\section{Hai Huang}

The lead subsurface computational scientist develops models to better understand the physics of fractures and fluids in tight rock formations. His team's models have gained significant interest from the oil and gas industry and resulted in growing funding opportunities from both DOE programs and industry.

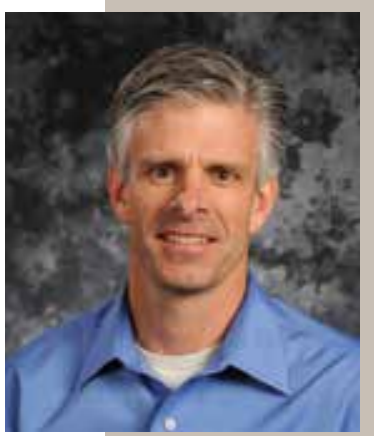

\section{Kevin Kenney}

The Biomass Feedstock National User Facility (BFNUF) director and his staff successfully introduced the capabilities and services of BFNUF through various meetings, trade shows and magazine articles, including an article in Innovation Magazine. His work resulted in a growing list of clients, including DuPont and Honeywell's Universal Oil Products. 


\section{Improving improvised explosive device deterrence}

The U.S. Department of Defense has recognized INL's capabilities for testing to defeat threats from improvised explosive devices (IEDs). INL's Wireless Test Bed is a preferred center for command and control of the Joint IED Defeat Organization's National Test Ranges. The test bed will enable DoD to enhance its technical testing capabilities, improve personal protection devices and reduce overall costs of operating the test ranges. In 2014, INL completed network connectivity with Naval stations at China Lake and Point Mugu, providing both stations access to one of DOE's world-class scientific user facilities 侖

\section{Expanding wireless spectrum availability}

To address the challenge of limited spectrum availability, INL hosted the 2014 National Wireless Research Symposium that convened leadership from emergency response organizations and important researchers from academia, industry and government. Participants met in research sessions and technical panels to discuss state-ofthe-art research and solutions needed to advance spectrum-using technologies. The symposium included a visit to INL's 890-square-mile outdoor Wireless National User Facility.

\section{Recognizing expertise}

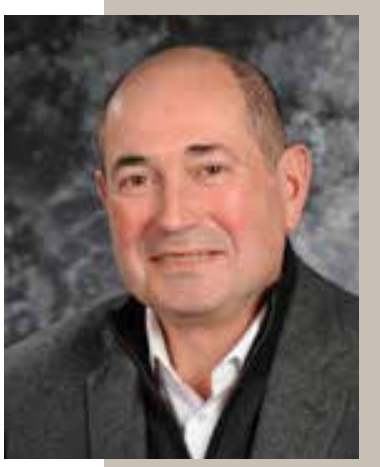

\section{Igor Bolshinsky}

In 2014, the senior scientist was part of a team honored a second time with a DOE Secretary's Achievement Award. Igor also received Hungary's Golden Cross of Merit, that country's highest national civilian award, for his assistance in removing high-enriched uranium from Hungary.

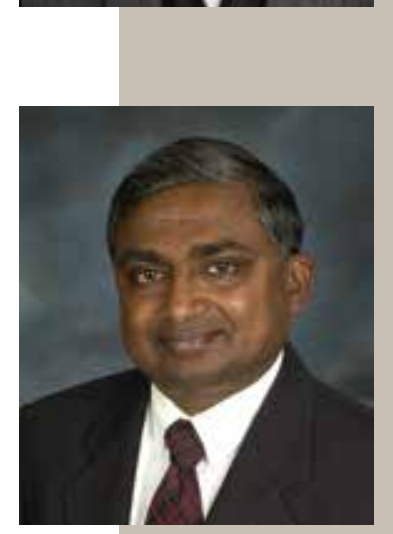

\section{Daniel Devasirvatham}

The director of INL's Wireless National User Facility provided technical input on security for the national public safety broadband communications network and helped develop the National Public Safety Telecommunications Council's report "Defining Public Safety Grade Systems and Facilities."

\section{Mike Tyacke}

The project manager was part of a team honored a second time with a DOE Secretary's Achievement Award for work with the Russian Research Reactor Fuel Return Program. This award recognized the significant progress in securing special nuclear materials from the threat of diversion to proliferation programs. 


\section{REGIONAL Leadership}

\section{Engaging regional stakeholders}

Energy resources concentrated along the U.S. and Canadian Rocky Mountains and northern plains are rich in diversity and offer a foundation for additional energy solutions. INL works to bring together multidisciplinary research partnerships because regional engagement will provide a foundation for advancing development of these resources.

\section{Improving efficiency of sola energy development}

Large-scale solar energy projects could progress more smoothly if developers had a tool to help avoid potential obstacles and identify optimal installation sites. A collaboration between INL, CAES, the Energy Policy Institute at Boise State University, Brigham Young University and DOE's SunShot Initiative has resulted in such a tool. PVMapper is an open-source online software tool for improving preliminary site screening and comparison for utility-scale photovoltaic projects. The geographic information system program can account for social constraints and preferences, land usage, geographical features, slope, and average solar exposure. PVMapper was created for large-scale solar energy projects but is also well-suited for other types of electricity generation plant site screening. $\lambda$

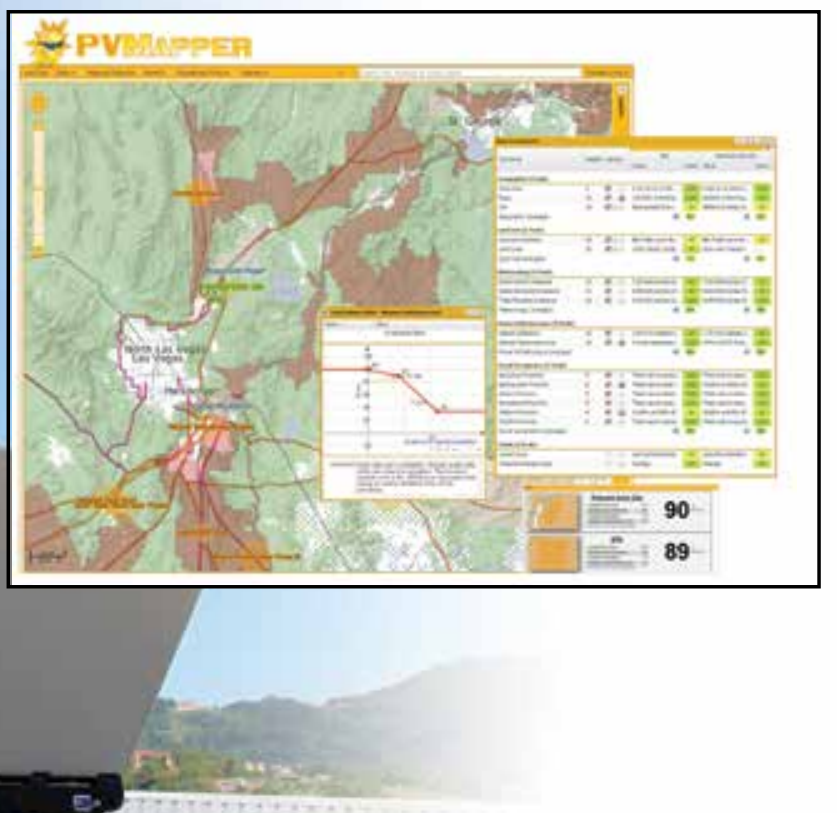



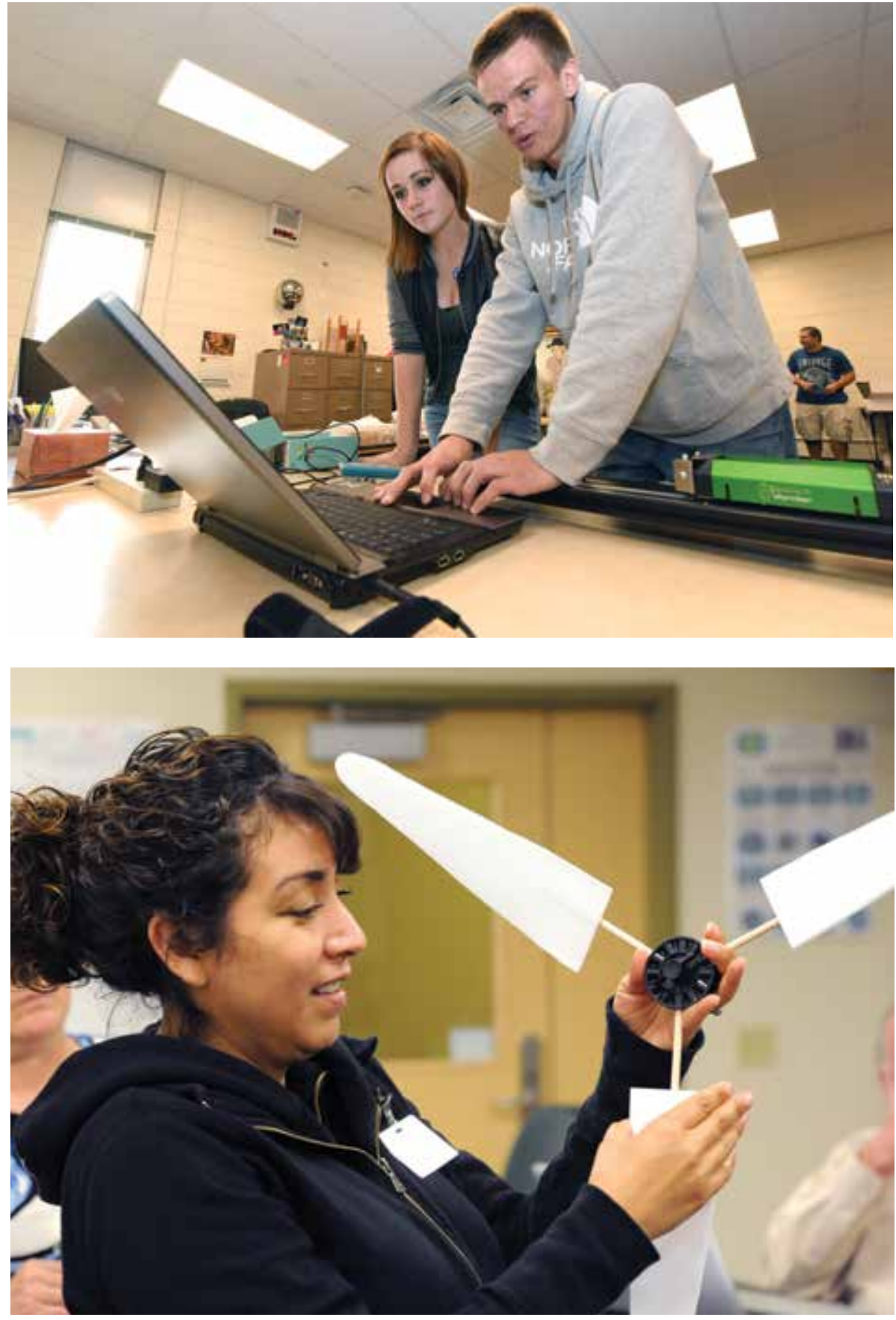

\section{Leading STEM education}

INL is a founding member of the Idaho STEM (i-STEM) initiative working to improve K-12 educational opportunities in Science, Technology, Engineering and Math. In FY 2014, i-STEM was recognized by the U.S. Department of Education and the International Association for Science, Technology, Engineering and Mathematics Leaders. The INL i-STEM team was also invited to join the 2014 STEM Innovations Conference focusing on "Overcoming STEM Education Barriers in Rural States."

In addition, the team received an invitation from Alaska's Nenana City Public School to partner with it to raise awareness for the need of a future STEM workforce in Alaska. The Alaska STEM institute hopes to benefit from the i-STEM model by incorporating elements of the program into its education rubric. 䯠 


\section{REGIONAL Leadership}

\section{Expanding research partnerships}

In FY 2014, the University of Wyoming joined the Center for Advanced Energy Studies at INL, a consortium of researchers from INL and Idaho's three public research universities. This addition broadens CAES' intellectual leverage and ability to compete for research grants. University of Wyoming programs focusing on energy and environment complement the research at CAES. The university's regional proximity, Wyoming's natural resources and its energy alliances also enhance the CAES talent breadth, academic recruitment, and research capabilities.

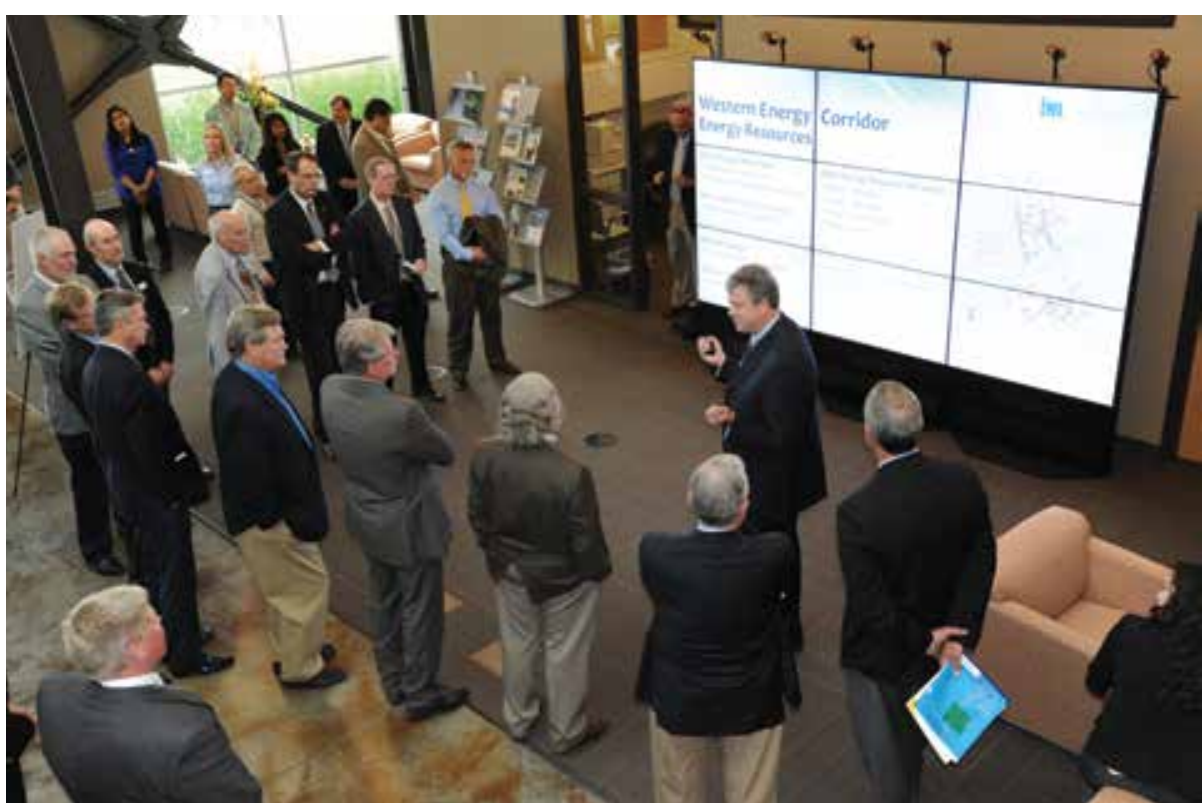

"The opportunity for Wyoming to participate with the

\section{Center for Advanced Energy Studies is phenomenal.}

We will be the first non-Idaho university to have that

\section{opportunity and we are most grateful."}

\section{- Wyoming Gov. Matt Mead}

\section{Facilitating regional dialogue, cooperation}

INL helped bring together scientists, government leaders, and energy company officials to establish regional dialogue on topics such as energy transmission, waste management, and budget. The lab sponsored and developed the inaugural Intermountain Energy Summit held August 2014 in Idaho Falls. Discussion occurred over two days and keynote speakers included U.S. Secretary of Energy Ernest Moniz, Idaho Gov. C.L. "Butch" Otter, the mayor of Idaho Falls, Idaho's U.S. senators and U.S. Rep. Mike Simpson. 而 ㅂ. 


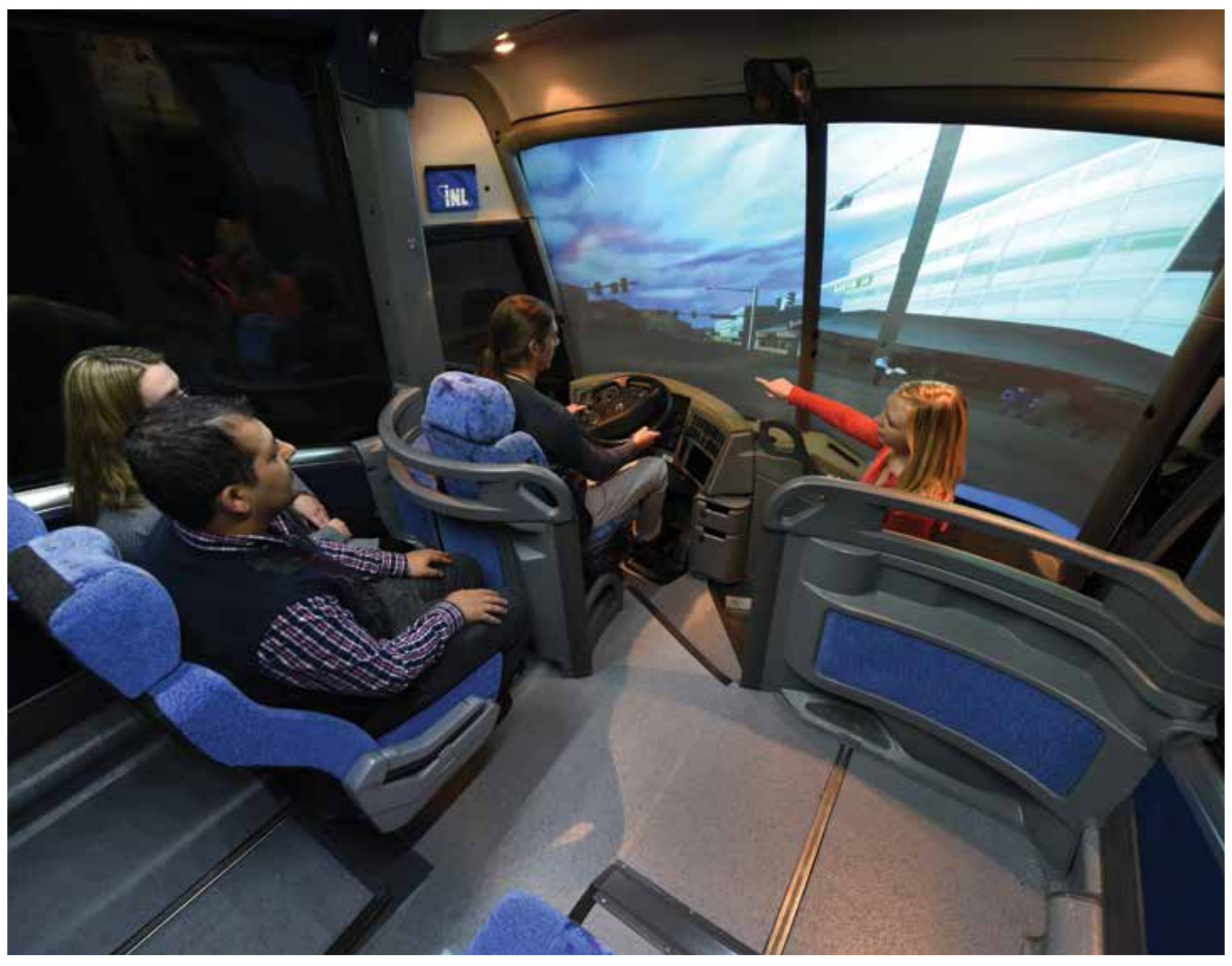

CAES researchers can now access new data to develop models for safe and fuel-efficient driving behaviors under various

conditions. A new state-of-the-art heavy vehicle simulator includes a front chassis, steering wheel, brakes and gas pedal that respond like a real 50,000-pound vehicle driving at $65 \mathrm{mph}$. 


\section{Only at INL}

\section{Unmatched capabilities}

INL's isolated geography and physical infrastructure provide unparalleled opportunities to test and demonstrate new technologies that help protect the nation's resources and advance energy security. The preceding pages have highlighted numerous capabilities that exist nowhere else in the U.S. The resources described here exemplify INL research assets that are truly unique to Idaho's national laboratory.

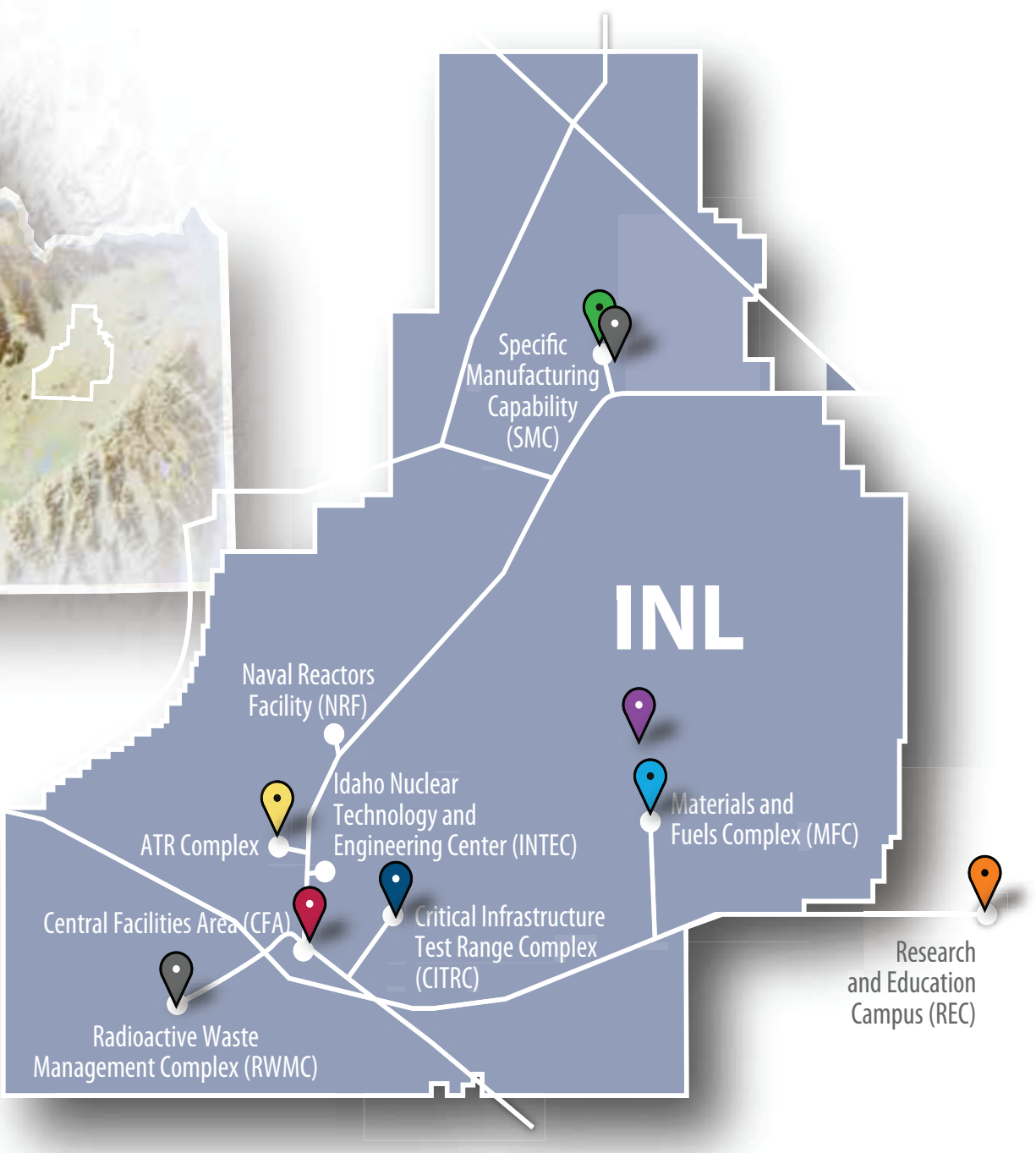


$\odot$ Advanced Test Reactor

$\ominus$ Analytical Lab

$\vartheta$ Fuel Conditioning Facility

$\ominus$ Hot Fuels Examination Facility

- Irradiation Assisted Stress Corrosion Cracking test rig

$\odot$ Space and Security Power Systems Facility

$\ominus$ - Transient Reactor Test Facility

- Utility-scale [60-mile] isolatable power grid

$\bullet$-Water Security Test Bed

$\vee$ Wireless Test Bed

$\odot$ Armor and explosives test range Nuclear \& Radiological Activity Center [multiple areas]

$\odot$ Radiological Response Training Range

$\odot$ Advanced Vehicle Testing Activity data analysis

$\odot$ Battery testing facilities

$\odot$ Biomass Process

Demonstration Unit

$\odot$ Carbon Characterization Laboratory

$\bigodot$ Dynamic Energy Storage Lab

$\odot$ Human System Simulation

$\vartheta$ Laboratory

$\odot$ High-temperature Test Lab

$\odot$ Microscopy and

Characterization Suite

$\ominus$ - National SCADA Test Bed

$\odot$ Specific Manufacturing Capability

National Scientific User Facilities

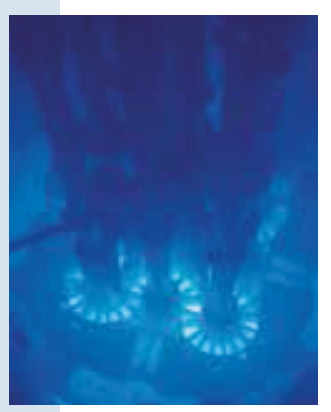

Advanced Test Reactor National Scientific User Facility

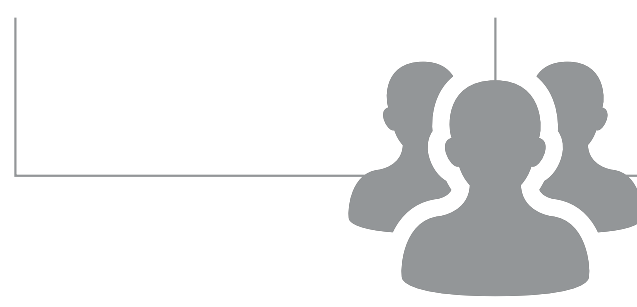

By the numbers:

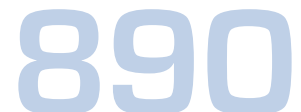

SQUARE MILES OF ISOLATED FACILITIES

IN IDAHO DESERT

NUMBER OF NATIONAL LABS

REPORTING DIRECTLY TO DOE'S

OFFICE OF NUCLEAR ENERGY

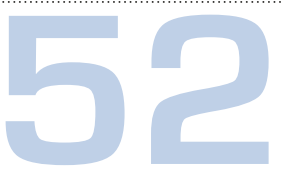

NUMBER OF MOSTLY FIRST-OF-THEIR-

KIND NUCLEAR REACTORS DESIGNED

AND BUILT AT WHAT IS NOW INL

ROUGH NUMBER OF PEOPLE WHO

TOUR INL FACILITIES EACH YEAR 
